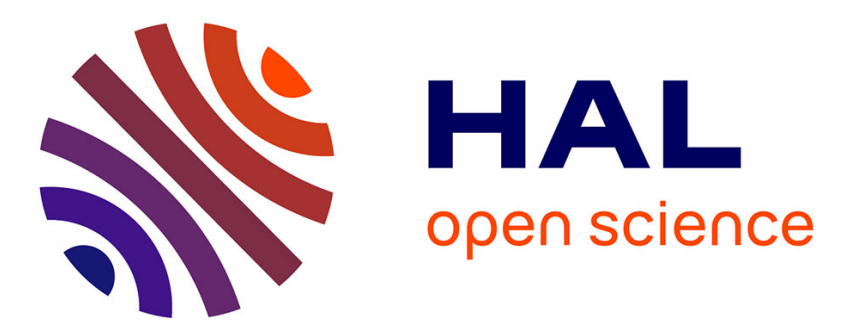

\title{
Electronic Properties of Poly-Yne Carbon Chains and Derivatives with Transition Metal End-Groups
}

Frederic Gendron, Thomas Groizard, Boris Le Guennic, Jean-Francois Halet

\section{To cite this version:}

Frederic Gendron, Thomas Groizard, Boris Le Guennic, Jean-Francois Halet. Electronic Properties of Poly-Yne Carbon Chains and Derivatives with Transition Metal End-Groups. European Journal of Inorganic Chemistry, 2020, 2020 (8), pp.667-681. 10.1002/ejic.201901112 . hal-02498321

\section{HAL Id: hal-02498321}

\section{https://hal-univ-rennes1.archives-ouvertes.fr/hal-02498321}

Submitted on 27 Mar 2020

HAL is a multi-disciplinary open access archive for the deposit and dissemination of scientific research documents, whether they are published or not. The documents may come from teaching and research institutions in France or abroad, or from public or private research centers.
L'archive ouverte pluridisciplinaire $\mathbf{H A L}$, est destinée au dépôt et à la diffusion de documents scientifiques de niveau recherche, publiés ou non, émanant des établissements d'enseignement et de recherche français ou étrangers, des laboratoires publics ou privés. 


\title{
Electronic Properties of Poly-yne Carbon Chains and Derivatives with Transition Metal End-Groups
}

\author{
Dr. Frédéric Gendron*, Dr. Thomas Groizard, \\ Prof. Dr. Boris Le Guennic, and Prof. Dr. Jean-François Halet* \\ Univ Rennes, CNRS, ISCR (Institut des Sciences Chimiques de Rennes) \\ UMR 6226, F-35000 Rennes, France
}

Email: frederic.gendron@univ-rennes1.fr and halet@univ-rennes1.fr

December 6, 2019

\begin{abstract}
During the three last decades, experimental chemists have forged a plethora of bimetallic molecular wires in which two redox-active metal termini are linked by a carbon-rich bridge. Their extensive redox chemistry with multiple, stepwise, one-electron oxidation processes provide them some interesting electronic and/or magnetic properties for potential applications. The nature of both the metal end-groups and the carbon bridge plays significant effect on the redox process, which is of paramount importance for the design of these systems. Indeed, examples of mono-oxidized complexes range from weakly coupled mixed-valence species through more strongly coupled systems in which the bridging ligand can be intimately involved in electron transfer processes. Similarly, di-oxidized species can encompass difference in magnetic behavior depending upon not only the nature of the framework of the systems but also the torsion angle between the terminal spin carriers, which allows the inversion of the singlet vs. triplet ground states. Theoretical quantum chemical computations have greatly assisted the development of this field of research. This review illustrates how, in synergy with experiments, computational results can provide additional valuable information on the nature of the localized vs. delocalized electronic communication in the mono-oxidized mixedvalence species, or the magnetic coupling differences and characteristics of the di-oxidized complexes.
\end{abstract}

"Carbon, in fact, is a singular element: it is the only element that can bind itself in long stable chains without a great expense of energy, and for life on earth precisely long chains are required." (The Periodic Table, Primo Levi) 


\section{Introduction}

The last three decades have witnessed a stunning collection of works devoted to the syntheses and characterizations of the redox properties, molecular and electronic structures of a variety of $\pi$-conjugated carbon-containing units spanning two transition metal organometallic termini. ${ }^{1-15}$ Much of the interest for these so-called molecular organometallic wires ${ }^{16}$ has been prompted by the rich redox chemistry of the different metal termini which encompass several transition metal elements such as, non-exhaustively, $\mathrm{Cr}, \mathrm{Mn}, \mathrm{Fe}, \mathrm{Co}, \mathrm{Mo}, \mathrm{Ru}, \mathrm{W}, \mathrm{Re}, \mathrm{Os}$, Pt, and Au organometallic fragments. ${ }^{17-80}$ Additionally, the efficiency of diverse linkers allows to convey electronic and magnetic communication between the termini. These compounds have received considerable attention due to the speculation that such assemblies would be well suited for use in a variety of applications in molecular electronics for instance. ${ }^{81-84}$

Combined with experimental studies, quantum-chemical calculations can aid to unravel the nature of the electronic and physical properties of these systems. ${ }^{85-90}$ Over the years, with the help of Kohn-Sham density functional theory (DFT) computations, we have ourselves analyzed and compared the electronic and geometrical structures of a large number of such molecular systems containing different carbon bridges and transition metal groups. ${ }^{12,14,91-93}$ More specifically, mostly in collaboration with Lapinte's and Bruce's groups, we have focussed on species containing the redox-active $\left[\left(\mathrm{PR}_{3}\right)_{2} \mathrm{Cp}\right.$ 'M] or $\left[(\mathrm{dppe}) \mathrm{Cp}\right.$ 'M] fragments $\left(\mathrm{M}=\mathrm{Fe}, \mathrm{Ru}, \mathrm{Os} ; \mathrm{PR}_{3}=\right.$ terminal

phosphine, dppe $=1$,2-bis(diphenylphosphino)ethane; $\mathrm{Cp}$ ' $=\mathrm{C}_{5} \mathrm{Me}_{5}$ or $\mathrm{C}_{5} \mathrm{H}_{5}$ ) linked to various $\pi$-conjugated poly-ynediyl ligands as depicted in Figure 1.

It turns out that these bimetallic complexes are perfectly designed for studying the potential electronic and magnetic communication that may exist between the different metal termini. Indeed, these poly-metallic complexes are stable under several oxydation states and the poly-ynediyl linker is particularly efficient in mediating electron transfer from one terminus to the other one. The main reason for this efficiency is the good match in energy between metal centered $\mathrm{d} \pi$-orbitals and the $\pi$-HOMOs of the carbon linker, which allows super-exchange electron-transfer processes. Introduction of aromatic rings such as benzene or thiophene in the anti-bonding spacer, or even non-conjugated spacers, constitutes an attractive possible modification to tune their electronic and magnetic properties. The first oxidation of the neutral complexes leads to compounds with mixed valence (MV) oxidation states. Depending on (i) the nature of the metal centers and (ii) the nature and length of the electron-conveyor carbon bridge, one may consider three different scenarios to characterize the electronic communication, as originally described by the Robin and Day classification. ${ }^{94}$ Here, systems with non-interacting metal-termini are labelled Class I, whereas strong communication arises in the fully delocalized valence systems of Class III. In between, Class-II complexes correspond to valence trapped systems, where some properties of localized $\mathrm{M}^{2+} / \mathrm{M}^{3+}$ 


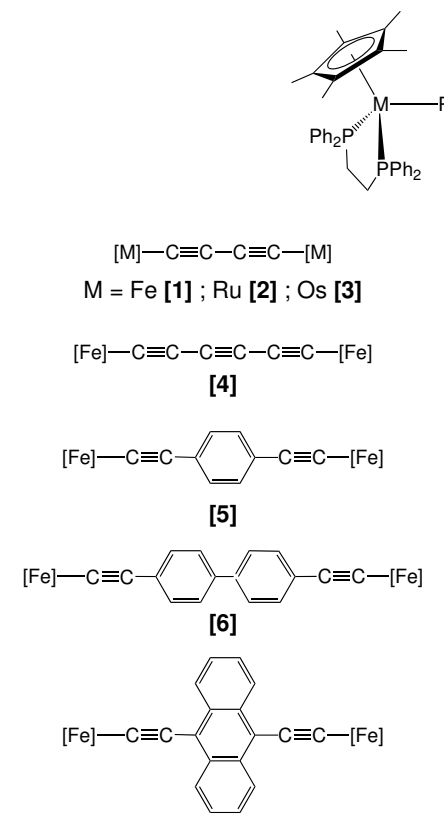

[7]

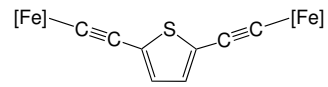

[8]
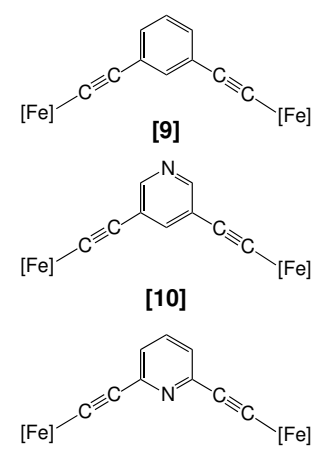

[11]

Figure 1: General picture and selection of metal-capped conjugated poly-yne carbon chains discussed in this manuscript. $[\mathrm{M}]=(\mathrm{dppe}) \mathrm{Cp}$ ' $\mathrm{M}$ and $(\mathrm{dpe}) \mathrm{CpM}$ for real and model compounds, respectively.

components are experimentally observable. One additional oxidation process often leads to stable dicationic species. In this case, the communication between the metal centers characterized by the magnetic coupling constant $(J)$, has revealed a large panel of interactions, such as diamagnetic, paramagnetic, antiferromagnetic and ferromagnetic, which may vary with the presence of different isomers or rotamers in equilibrium at room temperature. ${ }^{14}$

In this short review, theoretical results obtained over the years on different organometallic wires containing the iron, ruthenium and osmium organometallic electrophores are discussed to illustrate how the DFT machinery can be used in synergy with experiments to bring complementary information on the molecular structures, energies, as well as mixed-valence and magnetic properties of these molecular species.

\section{Electronic and bonding properties of the $\left\{\mathrm{MCpL}_{2}\right\}_{2}(\mu-\mathrm{C} \equiv \mathrm{C})_{n}$ series}

The electronic and redox properties of bimetallic complexes of general formula $\left\{\mathrm{MCpL}_{2}\right\}_{2}(\mu$ $\mathrm{C} \equiv \mathrm{C})_{n}(\mathrm{~L}=$ two-electron donor ligand) are strongly governed by the energy and the nodal properties of their frontier orbitals. Most of these complexes exhibit several oxidation states, which formally correspond to removal of one or several electrons in those frontier orbitals. A good un- 
derstanding of the electronic structure of these systems is therefore necessary in order to interpret and eventually modulate their physical properties.

\subsection{General orbital interaction picture}

The electronic structure of the $\left\{\mathrm{MCpL}_{2}\right\}_{2}(\mu-\mathrm{C} \equiv \mathrm{C})_{n}$ complexes can be simply described by analyzing the orbital interactions between the frontier orbitals (FOs) associated with the metallic fragment $\left[\left\{\mathrm{MCpL}_{2}\right\}_{2}\right]^{2+}$ with those of the poly-yne moiety $\left[(\mu-\mathrm{C} \equiv \mathrm{C})_{n}\right]^{2-} \cdot{ }^{95}$ Such an analysis, based on perturbation theory, gives a qualitative description of the electronic structure and the nature of the chemical bonding between the two fragments. A general qualitative orbital interaction diagram of such neutral model compounds is given in Figure 2. The metallic fragment $\left[\left\{\mathrm{MCpL}_{2}\right\}_{2}\right]^{2+}$ exhibits a set of eight FOs, which result of the in- and out-of-phase combinations of the $d$-type orbitals of the two non-interacting pseudo-ML ${ }_{5} d^{6}$ organometallic fragments. The metallic fragments are here sufficiently far apart that there are no interactions between them, and therefore the in- and out-of phase orbital combinations are almost degenerated. The two vacant orbitals, drawn on the left-hand side of Figure 2, result from the combinations of the radial hybrid orbitals $\mathrm{d}_{\sigma}$ and are energetically located above a set of six occupied orbitals. Among the latter ones, four are combinations of the $\mathrm{d}_{\pi}$ FOs and two are combinations of the $\mathrm{d}_{\delta}$ orbitals. It has to be mentioned that the charges on fragments have been chosen arbitrarily in order to be consistent with the octet rule for the carbon atoms of the $\left[(\mu-\mathrm{C} \equiv \mathrm{C})_{n}\right]^{2-}$ moiety. As illustrated on the righthand side of Figure 2, six carbon-based orbitals may interact with the metallic FOs of similar symmetries. They correspond to the occupied bonding $\pi$ - and $\sigma$-type orbitals, and to the vacant anti-bonding $\pi^{*}$-type orbitals.

The interaction between the two fragments is found mainly $\sigma$-type in character. Indeed, a strong $\sigma$ donation from the low-lying occupied $\sigma$ orbitals of the carbon spacer into the unoccupied high-lying metallic FOs leads to the formation of $\sigma$ bonds between the metal centers and their adjacent carbon atoms. Additionally, this interaction is complemented by a rather weak destabilizing $\pi$-type interaction between the occupied $\mathrm{d}_{\pi}$ orbitals and the occupied $\pi$-type orbitals of the $\left[(\mu-\mathrm{C} \equiv \mathrm{C})_{n}\right]^{2-}$ moiety. The resulting bonding and anti-bonding orbitals are occupied and are overall stabilized by some $\pi$-back donation from the occupied molecular orbitals $\left(\mathrm{d}_{\pi}-\pi\right)^{*}$ into the lowest empty $\pi^{*}$-type organic orbitals. Thus, the bond between the metallic fragments and the carbon spacer is mainly $\sigma$ in character with a weak $\pi$-back donation from the metal centers to the carbon chain. It formally corresponds to a single M-C bond. The anti-bonding orbitals $\left(\mathrm{d}_{\pi}-\pi\right)^{*}$ pictured in the center of Figure 2 correspond formally to the two first highest occupied molecular orbitals (HOMO and HOMO-1) of the neutral system $\left\{\mathrm{MCpL}_{2}\right\}_{2}(\mu-\mathrm{C} \equiv \mathrm{C})_{n}$. These orbitals are well separated from the rest of the occupied orbitals and are highly delocalized all over the 
metal-bridge-metal backbone. They $\operatorname{are} \mathrm{d}_{\pi} / \pi$ in character, anti-bonding between the metal atoms and the adjacent carbon atoms, and bonding between the carbon atoms triply bonded.

This general description of the electronic structure of these metal-end-capped carbon chain model complexes allows us to quantitatively understand the electronic properties of such systems when the theoretical studies are performed at a higher level of theory. Indeed, most of the calculations performed nowadays can be performed on the real molecules, which can somewhat complicate the energy level scheme. A theoretical study performed on both models and real compounds has shown that similarities between them largely overtake differences and that calculations on models provide quite acceptable results to provide information about the electronic properties of such species. ${ }^{93}$ For instance, the electronic properties of the homo-bimetallic $\left\{\mathrm{Fe}(\mathrm{dppe}) \mathrm{Cp}^{*}\right\}_{2}(\mu-$ $\mathrm{C} \equiv \mathrm{C})_{2}$ complex $^{96,97}$ (see [1] in Figure 1), were studied with the aid of DFT using the model compound $\{\mathrm{Fe}(\mathrm{dpe}) \mathrm{Cp}\}_{2}(\mu-\mathrm{C} \equiv \mathrm{C})_{2},\left[\mathbf{1}^{\prime}\right]{ }^{79}$ The resulting electronic structure obtained at this level of theory was found qualitatively similar to the one sketched in Figure 2. The contour plots of the first frontier orbitals for the model compound [1'] are shown in Figure 3. The LUMO and LUMO+1 are metal-ligand (dpe, $\mathrm{Cp}$ ) anti-bonding in character and arise from the $e_{g}$ metallic orbitals of the pseudo $\mathrm{ML}_{5}$ fragments. Similarly to the previous qualitative diagram, the two first HOMOs are $\mathrm{d}_{\pi} / \pi$ type in character and are delocalized all over the $\mathrm{Fe}-\mathrm{C}_{4}-\mathrm{Fe}$ backbone. The atomic percentage contributions of these HOMOs, given in Figure 3, reveal that the HOMO and HOMO-1 of [1']

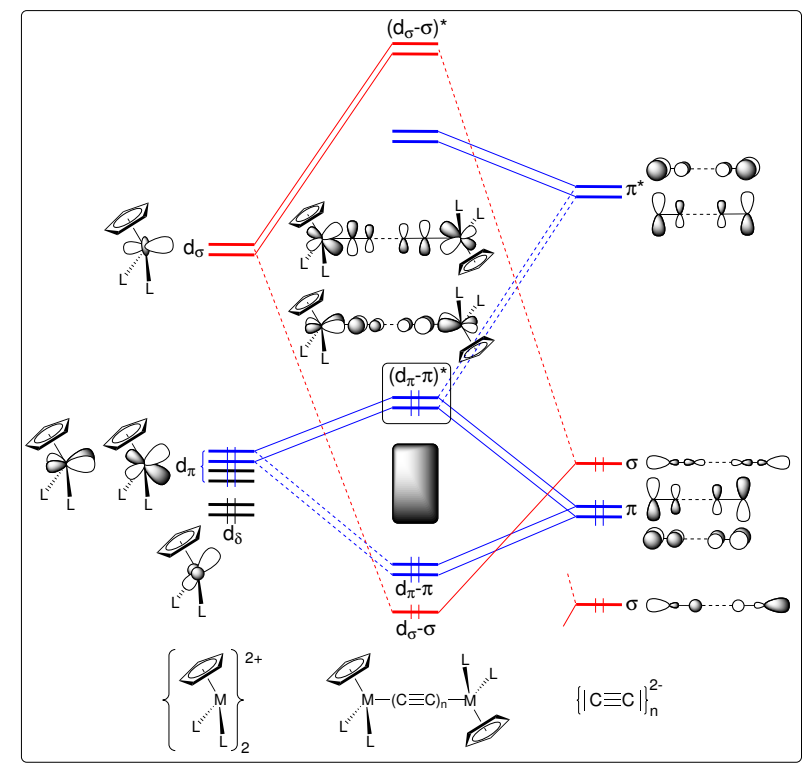

Figure 2: Qualitative orbital interaction diagram between the frontier orbitals of the metallic fragment $\left[\left\{\mathrm{MCpL}_{2}\right\}_{2}\right]^{2+}$ and a poly-yne carbon chain $\left[(\mu-\mathrm{C} \equiv \mathrm{C})_{n}\right]^{2-}$ for the $\left\{\mathrm{MCpL}_{2}\right\}_{2}(\mu-\mathrm{C} \equiv \mathrm{C})_{n}$ complexes. 

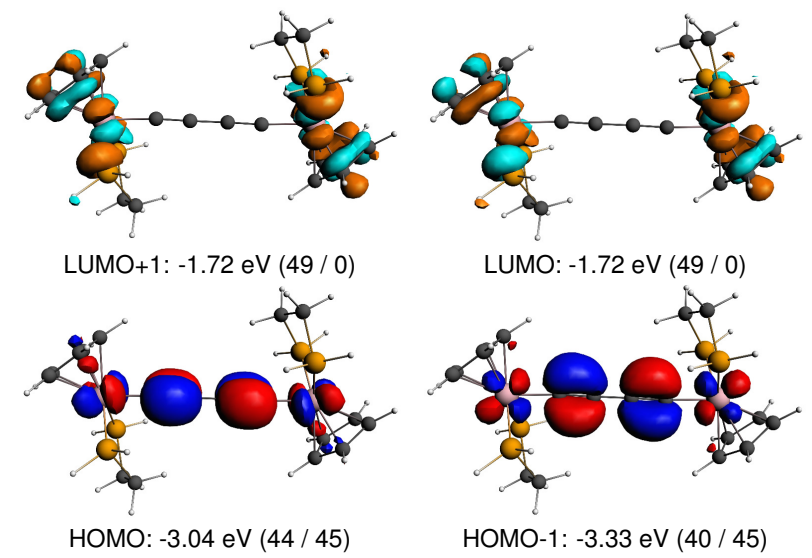

LUMO: $-1.72 \mathrm{eV}(49$ / 0)

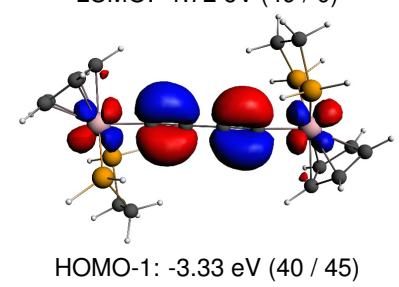

Figure 3: DFT contour plots, energies and $\mathrm{Fe}_{2} /(\mu-\mathrm{C} \equiv \mathrm{C})_{2}$ percentage contributions of the first frontier orbitals for the model compound [1']. Iso-contours: $\pm 0.03 \mathrm{au}$.

are both metallic and organic in character with roughly $40 \%$ and $50 \%$ on the iron atoms and on the carbon bridge, respectively.

\subsection{Influence of the metallic termini on the electronic structure}

As said earlier, a large panel of bimetallic complexes, containing a conjugated poly-yne carbon chain as organic bridge, were synthesized and characterized over the last decades. ${ }^{2,12,14}$ As previously described for the iron complex [1'], the first HOMOs for these systems are both metallic and organic in character. However, the relative percentage contributions in these HOMOs strongly depend upon the nature of the metallic fragments. Electrochemical measurements performed on the $\left\{\mathrm{MCp}^{\prime} \mathrm{L}_{2}\right\}_{2}(\mu-\mathrm{C} \equiv \mathrm{C})_{2}$ series have shown that all of these complexes can exhibit at least two reversible one-electron oxidation processes. Nevertheless, both experimental and theoretical studies have shown that the electronic communication between the redox centers strongly differs according to the nature of the metal fragments, suggesting that the organic moiety $(\mu-\mathrm{C} \equiv \mathrm{C})_{2}$ contributes differently to the HOMOs of these complexes. Indeed, depending on the nature of the metallic fragment, the oxidation process will involve HOMOs which can be either (i) preferentially localized on the metal centers, (ii) delocalized on all over the $\mathrm{M}-(\mu-\mathrm{C} \equiv \mathrm{C})_{2}-\mathrm{M}$ backbone or (iii) preferentially localized on the organic bridge.

Using DFT calculations, the influence of the nature of the metal atoms on the electronic and redox properties of the $\left\{\mathrm{MCpL}_{2}\right\}_{2}(\mu-\mathrm{C} \equiv \mathrm{C})_{2}$ complexes were first rationalized with studies performed on isoelectronic model compounds of general formula $\{\mathrm{M}(\mathrm{dpe}) \mathrm{Cp}\}_{2}(\mu-\mathrm{C} \equiv \mathrm{C})_{2}$, with metals from the Group-8 triad ( $\mathrm{M}=\mathrm{Fe}, \mathrm{Ru}$ et Os) ${ }^{76,77}$ Such model compounds are of great interest in order to compare the effect of the nature of metal atoms onto the electronic properties since they 


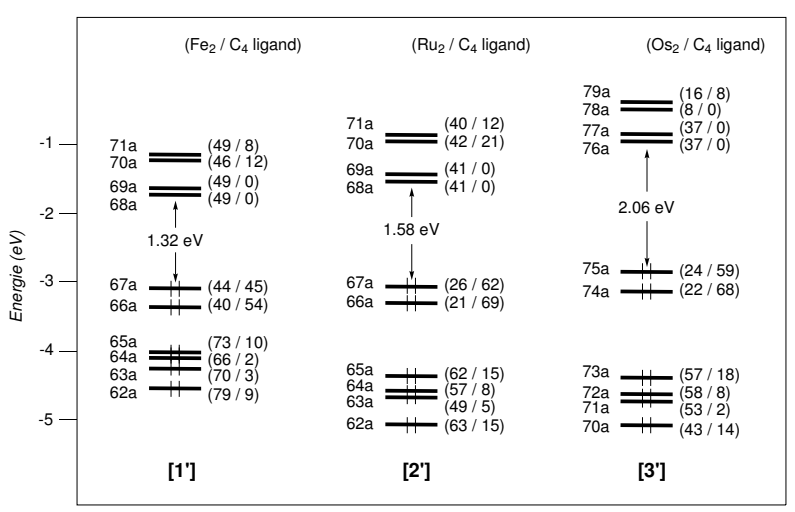

Figure 4: DFT molecular orbital diagrams of the $\{\mathrm{M}(\mathrm{dpe}) \mathrm{Cp}\}_{2}(\mu-\mathrm{C} \equiv \mathrm{C})_{2}$ series with $\mathrm{M}=\mathrm{Fe}, \mathrm{Ru}$ and Os. The $\mathrm{M}_{2} /(\mu-\mathrm{C} \equiv \mathrm{C})_{2}$ percentage contributions of the MOs are given in parentheses. See Reference [76] for more details.

contain exactly the same ancillary ligand sphere. The molecular orbitals diagrams of these three model compounds are shown in Figure 4. The energy level scheme is hardly modified when iron atoms of complex [1'] are replaced by either ruthenium or osmium atoms. In each case, the two first HOMOs are isolated from the other metallic MOs and are well separated from the high-lying LUMOs by a large energy gap (largely over $1 \mathrm{eV}$ using the GGA BP86 functional, ${ }^{98,99}$ confirming the thermodynamic stability of these species regardless of the nature of the metal atoms. However, some small differences are noted. Energies of the first frontier orbitals are modified upon the change of metal centers. For instance, the substitution of iron atoms by ruthenium ones leads to a slight energetic stabilization of the HOMO and to a more important destabilization of the LUMOs, which consequently, affords an increase of the HOMO-LUMO energy gap. The nodal and spatial properties of the first frontier orbitals are also modified. We have previously seen that the two first HOMOs of [1'] are delocalized all over the $\mathrm{Fe}-\mathrm{C}_{4}$-Fe backbone with both organic and metallic character of roughly $40 \%$ (see Figure 4). Replacement of the iron atoms by ruthenium in [2'] or osmium in [3'] ones yields HOMOs more heavily weighed on the carbon bridge. For instance, the Ru contributions to the HOMO and HOMO-1 in [2'] is of ca. $25 \%$, whereas the organic character is over $60 \%$. Thus, the oxidation process of ruthenium-based complexes should mainly affect the organic bridge, but metals in the iron-based complexes. These theoretical results are consistent with the infra-red (IR) spectroscopic data obtained for the $\left[\left\{\mathrm{M}(\mathrm{dppe}) \mathrm{Cp}^{*}\right\}_{2}(\mu-\mathrm{C} \equiv \mathrm{C})_{2}\right]^{n+}$ series, and especially with the $v(\mathrm{C} \equiv \mathrm{C})$ bands, which reveal a stronger reducing in the $\mathrm{C} \equiv \mathrm{C}$ bonding character upon oxidation of the ruthenium complexes than the iron ones. This will imply some differences in their physical properties as we will see later.

The influence of the nature of the metal atoms on the redox properties of the $\{\mathrm{M}(\mathrm{dpe}) \mathrm{Cp}\}_{2}(\mu$ $\mathrm{C} \equiv \mathrm{C})_{2}$ series, were also studied for the mixed species of formula $\{\mathrm{Fe}(\mathrm{dpe}) \mathrm{Cp}\}(\mu-\mathrm{C} \equiv \mathrm{C})_{2}\{\mathrm{Ru}(\mathrm{dpe}) \mathrm{Cp}\} .{ }^{77}$ 
Interestingly, the nodal properties of the HOMOs of this hetero-bimetallic complex are found to be intermediate between those of the analogous homo-bimetallic congeners. The metallic character of the HOMO is $30 \%$, with as expected, a more important contribution on the iron center than on the ruthenium one (18\% vs. $12 \%)$, whereas the participation of the $(\mu-\mathrm{C} \equiv \mathrm{C})_{2}$ bridge remains important with a contribution of $57 \%$. This behavior can simply be rationalized with the evolution of the spatial extension of the metal $d$ orbitals when going from Fe to Os. The more diffuse character of the $5 d$ and $4 d$ orbitals compared to their $3 d$ analogues, leads to a larger overlap with the carbon $\pi$ orbitals, and hence, tends to increase the electron delocalization over the carbon spacer. Thus, in summary, theoretical studies performed on bimetallic compounds of formula $\{\mathrm{M}(\mathrm{dpe}) \mathrm{Cp}\}_{2}(\mu-\mathrm{C} \equiv \mathrm{C})_{2}$ with Group-8 metals, have shown that their first occupied orbitals are rather delocalized all over the $\mathrm{M}-\mathrm{C}_{4}-\mathrm{M}$ backbone, the bridge character being more important for the ruthenium- and osmium-based compounds than for the iron-based ones. This delocalization suggests that the organic bridge will also be affected upon oxidation.

\subsection{Influence of the oxidation process on the valence bond structure}

The previous description of the electronic structure of the $\left\{\mathrm{MCpL}_{2}\right\}_{2}(\mu-\mathrm{C} \equiv \mathrm{C})_{n}$ complexes and the analysis of the nodal properties of their HOMOs allow to understand the geometrical changes that occur upon the several oxidation processes of these complexes. These changes can be illustrated with a glance at the model compounds [2'] ${ }^{m+}$ issued from of [2] ${ }^{m+}$ for which five redox states, from $m=0$ to 4 , were experimentally observed (see results in Table 1). ${ }^{95}$ Oxidation of the neutral compound [2'] does not affect the rigidity of the organic bridge. The computed angles for the Ru$\mathrm{C}_{4}-\mathrm{Ru}$ skeleton remain similar and close to $180^{\circ}$, regardless of the oxidation state of the complex. On the other hand, the successive loss of four electrons in [2'] leads to a strong shortening of the bond lengths between the Ru centers and the first adjacent carbon atoms. These distances decrease from 2.028 to $1.850 \AA$ when going from the neutral to the tetra-cationic complexes, respectively. A substantial shortening of $0.093 \AA$ is also computed for the central $\mathrm{C}_{\beta}-\mathrm{C}_{\beta}^{\prime}$ single bond between

Table 1: Pertinent optimized distances $(\AA)$ and angles $\left(^{\circ}\right)$ for the model compounds $\left[\mathbf{2}^{\prime}\right]^{m+}$ series, with $m=0-4$.

\begin{tabular}{|c|c|c|c|c|c|}
\hline Compd & $\mathrm{Ru}-\mathrm{C}_{\alpha}$ & $\mathrm{C}_{\alpha}-\mathrm{C}_{\beta}$ & $\mathrm{C}_{\beta}-\mathrm{C}_{\beta}^{\prime}$ & $\mathrm{Ru}-\mathrm{C}_{\alpha}-\mathrm{C}_{\beta}$ & $\mathrm{C}_{\alpha}-\mathrm{C}_{\beta}-\mathrm{C}_{\beta}^{\prime}$ \\
\hline [2'] & 2.028 & 1.241 & 1.369 & 176.4 & 176.8 \\
\hline$\left[2^{\prime}\right]^{+}$ & 1.973 & 1.258 & 1.339 & 176.1 & 177.2 \\
\hline$\left[2^{\prime}\right]^{2+}(\mathrm{S})$ & 1.926 & 1.275 & 1.317 & 176.0 & 177.3 \\
\hline$\left[2^{\prime}\right]^{2+}(\mathrm{T})$ & 1.918 & 1.281 & 1.311 & 176.2 & 177.2 \\
\hline$\left[2^{\prime}\right]^{3+}(\mathrm{D})$ & 1.886 & 1.301 & 1.292 & 176.1 & 177.4 \\
\hline$[2]^{4+}(\mathrm{S})$ & 1.850 & 1.333 & 1.276 & 176.5 & 177.1 \\
\hline
\end{tabular}

(S): Singlet state, (T): Triplet state, (D): Doublet state. 


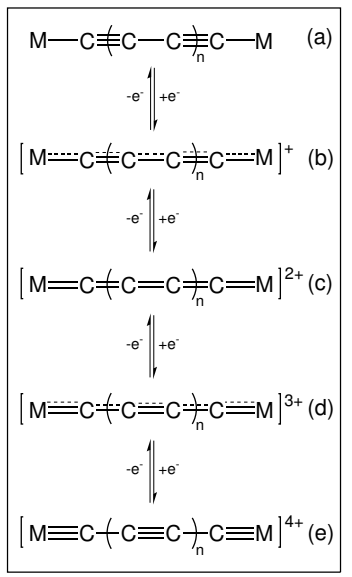

Figure 5: Valence bond structure of the carbon bridge in the $\left[\left\{\mathrm{MCpL}_{2}\right\}_{2}(\mu-\mathrm{C} \equiv \mathrm{C})_{n}\right]^{m+}$ series as a function of the oxidation state. Adapted from Reference [95].

these two oxidation states. The triple carbon bonds $\left(\mathrm{C}_{\alpha}-\mathrm{C}_{\beta}\right)$ are lengthened upon oxidation with $\mathrm{C}_{\alpha}-\mathrm{C}_{\beta}$ distances of 1.241 and $1.333 \AA$ for $m=0$ and 4 , respectively. These changes in the interatomic distances in the $\mathrm{Ru}-\mathrm{C}_{4}-\mathrm{Ru}$ backbone can be understood with the analysis of the spatial and nodal properties of the two first HOMOs of the neutral compound [2']. Similarly to iron complex [1'], the HOMO and HOMO-1 are anti-bonding in character between the ruthenium atoms and the first adjacent carbon atoms and between the carbon atoms singly bonded. Consequently, removal of one up to four electrons from these two HOMOs leads to a decrease of the anti-bonding character between the $\mathrm{Ru}$ and $\mathrm{C}_{\alpha}$ atoms and between the $\mathrm{C}_{\beta}$ and $\mathrm{C}_{\beta}^{\prime}$ atoms, which affords bond distance shortening. By contrast, depopulation of these HOMOs leads to a decrease of the bonding character between the carbon atoms triply bonded, causing some bond distance lengthening.

The evolution of the interatomic distances of the $\mathrm{Ru}-\mathrm{C}_{4}-\mathrm{Ru}$ backbone upon oxidation of [2'] ${ }^{m+}$, can also be observed for the other compounds of the $\left[\left\{\mathrm{MCpL}_{2}\right\}_{2}(\mu-\mathrm{C} \equiv \mathrm{C})_{n}\right]^{m+}$ series. A more general description of the valence bond structure of the organic bridge for these systems as a function of the oxidation state is illustrated in Figure 5. For the neutral complexes $\left\{\mathrm{MCpL}_{2}\right\}_{2}(\mu-\mathrm{C} \equiv \mathrm{C})_{n}$, the carbon spacer adopts a poly-yne structure (see Figure 5-a). The metal atoms form single bonds with their adjacent carbon atoms and the rest of the bonds of the bridge correspond to alternating triple $\mathrm{C} \equiv \mathrm{C}$ and single $\mathrm{C}-\mathrm{C}$ bonds. Formally, the first removal of one electron leads to some lengthening of the triple bond and to a shortening of the single bonds. The second oxidation increases these geometrical changes and leads to a more cumulenic carbon chain, with formally double $\mathrm{M}=\mathrm{C}$ and $\mathrm{C}=\mathrm{C}$ bonds (Figure 5-c). Finally, additional double oxidation affords the tetracationic $\left[\left\{\mathrm{MCpL}_{2}\right\}_{2}(\mu-\mathrm{C} \equiv \mathrm{C})_{n}\right]^{4+}$ species (Figure 5-e), with once again a poly-yne structure and triple bonds being formed between metal centers and outer carbon atoms. 

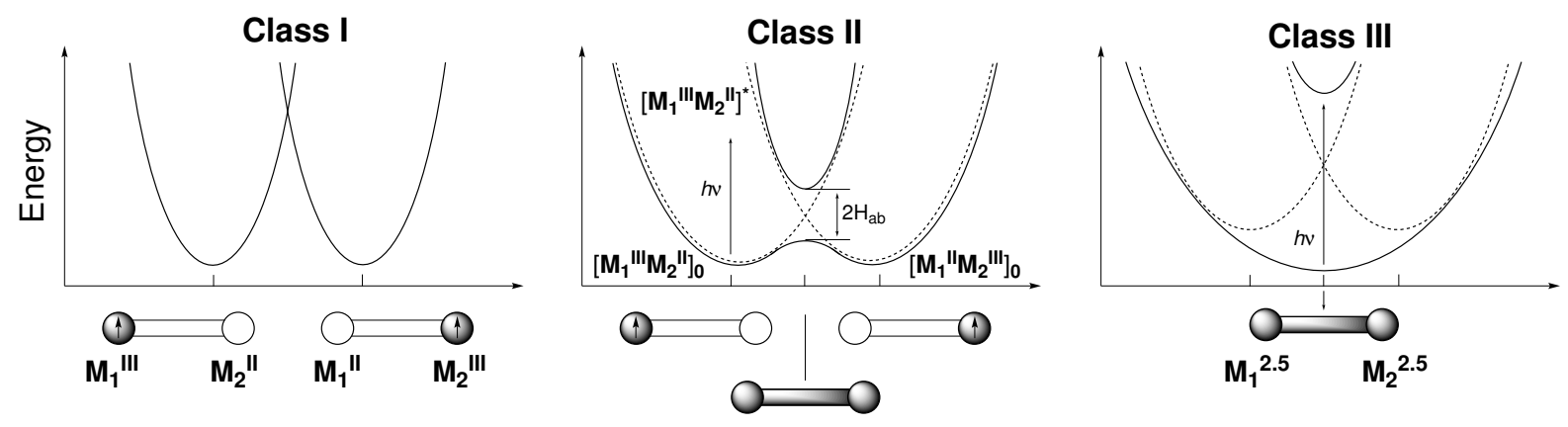

Q, Reaction Coordinates

Figure 6: Potential energy curves for electron transfer in bimetallic complexes according to the Robin and Day classification. Class-I compounds with localized electrons (left), Class-II compounds with weak electronic communication via delocalized excited state (middle), and Class-III compounds with strong electronic communication and delocalized electron (right). See Reference [103] for more details.

\section{One electron less: toward mixed-valence complexes}

The first one-electron oxidation process of the $\left\{\mathrm{MCpL}_{2}\right\}_{2}(\mu-\mathrm{C} \equiv \mathrm{C})_{n}$ series affords complexes with formal mixed-valence oxidation states. In such systems, according to the magnitude of the electronic communication between the metallic fragments, the spin density can be either (i) localized on one single redox center, (ii) shared between both metallic termini or (iii) delocalized all over the entire metal-carbon-metal linker, which leads to very different electronic and physical properties. In 1967, Robin and Day have established an empirical classification which, depending on the strength of the electronic interaction between the remote redox centers, characterizes these systems in three different classes. ${ }^{94}$ The electronic properties of these three classes strongly differ, and can be rationalized with the help of a two-center model using the Marcus-Hush theory as shown in Figure 6. ${ }^{100-102}$

A complex with no interaction between the redox centers belongs to Class I. Such complexes are similar to those of two independent metallic fragments and the charge, or the unpaired electron, remains localized on one redox center. Weak electronic interactions between the two metal centers are characteristic of Class-II compounds. These complexes display their own electronic and optical properties, such as inter-valence bands in the near infra-red (NIR). These electronic transitions correspond to charge transfer between the two redox centers via a delocalized excited state. The electronic interaction in such systems remains sufficiently weak to be able to localize the unpaired electron at a measurable time-scale. Finally, Class-III mixed-valence complexes correspond to 
systems where a strong electronic interaction occurs between the two metallic end-groups. Here, the electronic interaction between the redox centers is so important that the spin density is delocalized all over the entire complex and it is not possible to differentiate the metallic fragments. This qualitative classification has been intensively used in order to evaluate the electronic properties of mixed-valence complexes, but presents some limitations, especially for systems where the organic bridge behaves as a non-innocent ligand and takes part to the delocalization of the spin density. In this case, systems display electronic properties which are often between Class II and Class III. Recently, new models have been proposed to rationalize the physical properties of such systems. ${ }^{103-105}$

\subsection{Electronic communication in the $\left[\left\{\mathrm{MCpL}_{2}\right\}_{2}(\mu-\mathrm{C} \equiv \mathrm{C})_{n}\right]^{+}$complexes}

As expected from the analysis of the HOMOs of the neutral complexes, removal of one electron in the HOMO of such complexes leads to mono-oxidized species where the distribution of the spin density must differ according to the nature of the metallic fragments and/or to the length of the carbon spacer. For instance, the spin density distribution strongly differs between the mono-oxidized model compounds [1'] $]^{+}$and [2'] ${ }^{+}$. For the di-iron complex [1'] $]^{+}$, the spin density is mainly localized on the iron centers $(0.65 \mathrm{e})$ and to a lesser extent, on the carbon chain $(0.39 \mathrm{e}){ }^{77}$ In contrast, in the Ru-based complex [2'] ${ }^{+}$, the spin density on the organic bridge is more important (0.56 e), whereas only $0.35 \mathrm{e}$ is found on the Ru atoms. ${ }^{77}$ For the hetero-bimetallic species $[\{\mathrm{Fe}(\mathrm{dpe}) \mathrm{Cp}\}(\mu$ $\left.\mathrm{C} \equiv \mathrm{C})_{2}\{\mathrm{Ru}(\mathrm{dpe}) \mathrm{Cp}\}\right]^{+}$, the spin density is also mostly localized on the carbon spacer $(0.51 \mathrm{e})$ but the metallic character remains important $(0.45 \mathrm{e})$, with 0.29 and $0.16 \mathrm{e}$ on the Fe and Ru centers, respectively. Overall, for the $\left[\left\{\mathrm{MCpL}_{2}\right\}_{2}(\mu-\mathrm{C} \equiv \mathrm{C})_{n}\right]^{+}$series, where $n=1$ and 2 , the large delocalization of the spin density on the carbon spacer is consistent with the experimental data (EPR, IR and near-IR), and contributes to classify theses systems as mixed-valence Class-III complexes, with the poly-yne chain acting as a non-innocent ligand and strongly participating to the electronic communication between the $\mathrm{MCpL}_{2}$ centers. In the case of complexes containing longer poly-yne chains $(\mathrm{n}>4)$, as for instance with the homo-bimetallic complex $\left[\left\{\mathrm{Fe}(\mathrm{dppe}) \mathrm{Cp}^{*}\right\}_{2}(\mu-\mathrm{C} \equiv \mathrm{C})_{4}\right]^{+}$, the calculated contribution of the carbon chain strongly increases, ${ }^{106}$ suggesting stronger electronic communication between the metal centers. However, the experimental studies have clearly shown that the lengthening of the carbon chain leads to (i) a decrease of the thermodynamic stability of the oxidized species ${ }^{107}$ and (ii) to a decrease of the electronic coupling between the remote redox centers. ${ }^{106}$ Therefore, in order to have both stable oxidized bimetallic complexes and important communication between the metal end-groups as the carbon chain lengthens, it is necessary to modify the nature of the organic bridge as detailed below. 


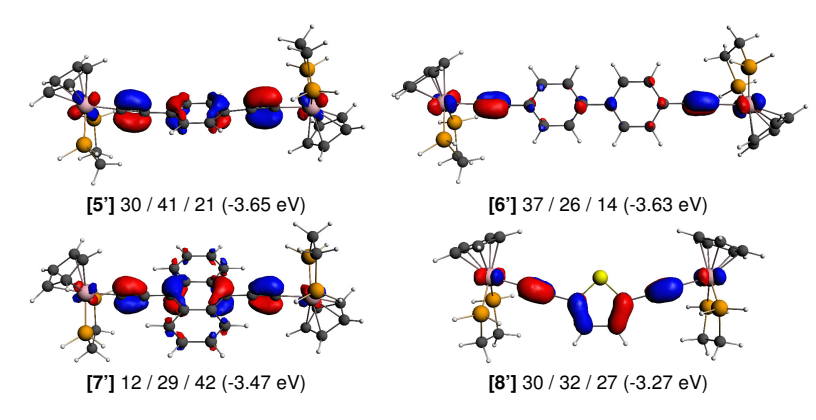

Figure 7: DFT contour plots, $\mathrm{Fe}_{2} /(\mathrm{C} \equiv \mathrm{C})_{2} / \mathrm{Ar}$ percentage contributions and energies of the HOMO for the model compounds [5'], [6'] [7'] and [8']. Iso-contours: \pm 0.03 au.

\subsection{Modification of the carbon linker to tune electronic communication}

Introduction of an aromatic ring into the carbon chain can constitute an attractive solution in order to enhance the electronic coupling between metallic fragments and to circumvent the instability of the oxidized species with very long carbon spacers. Experimentally, the influence of the insertion of an aromatic ring on the electronic properties of the $\left\{\mathrm{MCpL}_{2}\right\}_{2}(\mu-\mathrm{C} \equiv \mathrm{C})_{n}$ complexes were intensively studied in Lapinte's group with the synthesis of a large series of di-iron complexes of general formula $\left[\mathrm{Fe}(\mathrm{dppe}) \mathrm{Cp}^{*}\right]_{2}(\mu-\mathrm{C} \equiv \mathrm{C}-\mathrm{Ar}-\mathrm{C} \equiv \mathrm{C})$, with $\mathrm{Ar}=\left(1,4-\mathrm{C}_{6} \mathrm{H}_{4}\right)[\mathbf{5}]{ }^{108}\left(4,4-\left(\mathrm{C}_{6} \mathrm{H}_{4}\right)_{2}\right)$ [6] ${ }^{109}\left(1,4-\mathrm{C}_{14} \mathrm{H}_{8}\right)[7],{ }^{110}$ and $\left(2,5-\mathrm{SC}_{4} \mathrm{H}_{2}\right)$ [8] for instance. ${ }^{111,112}$ These compounds exhibit ironterminus distances that are similar to those encountered in the $\left\{\mathrm{Fe}(\mathrm{dppe}) \mathrm{Cp}^{*}\right\}_{2}(\mu-\mathrm{C} \equiv \mathrm{C})_{4}$ complex (roughly $12 \AA$ ), allowing to precisely evaluate the role played by the aromatic rings on the electronic properties. These latter were first understood with the help of DFT studies carried out on the corresponding model compounds $[\mathrm{Fe}(\mathrm{dpe}) \mathrm{Cp}]_{2}(\mu-\mathrm{C} \equiv \mathrm{C}-\mathrm{Ar}-\mathrm{C} \equiv \mathrm{C}) .{ }^{113}$

Insertion in para position of an aromatic ring into the carbon chain for instance, such as a para-phenylene unit (see [5] in Figure 1), hardly affects the nature of the first frontier orbitals. The HOMO of [5'] for instance, shown in Figure 7, is $\mathrm{d} \pi / \pi$-type in character and is fully delocalized on both iron atoms (30\%), on the ethynyl moieties (41\%) and to a lesser extent, on the aromatic ring $(21 \%)$. Spin density calculations performed on the mono-oxidized species [5' $]^{+}$ have shown that the unpaired electron distribution follows a trend similar to that computed for $\left[\mathbf{1}^{\prime}\right]^{+}$, i.e., delocalized over the whole framework, where the electronic properties are characteristic of a mixed-valence complex intermediate between Class II and Class III of the Robin and Day classification. ${ }^{110}$

Surprisingly enough, introduction of a second para-phenylene unit in $[6]^{+}$strongly diminishes the electronic coupling between the iron fragments, leading to a mixed-valence Class-II complex (valence-trapped at short time scale). Indeed, it turns out that due to steric hindrance the two aromatic rings cannot be coplanar, breaking somewhat the conjugated pathway along the organic 
bridge. This is illustrated by the smaller $\left(\mathrm{C}_{6} \mathrm{H}_{4}\right)_{2}$ character $(14 \%)$ in the HOMO of the corresponding neutral complex [6'] compared to the $\mathrm{C}_{6} \mathrm{H}_{4}$ character found in the HOMO of [5'] (21 $\%)$. If we assume that the electronic and geometrical reorganizations are not too important upon oxidation, the spin density distribution should mainly be localized on the metallic centers, leading to a valence-localized species (Class II). Insertion of an anthracene ring in complex [7'] results in a strong increase of the aromatic character in the HOMO of the neutral system $(42 \%) .{ }^{110}$ Such a strong aromatic character was also observed in the corresponding singly oxidized species, with the major part of the spin density mostly localized on the ( $\mu$-C $\left.\equiv \mathrm{C}-\left(1,4-\mathrm{C}_{14} \mathrm{H}_{8}\right)-\mathrm{C} \equiv \mathrm{C}\right)$ spacer, allowing a strong electronic communication between both iron termini. Similarly, the use of a thiophene group in the organic bridge leads to the cationic system $[\mathbf{8}]^{+}$showing the electronic properties of a strongly coupled mixed-valence Class-III complex. ${ }^{111,112}$ The atomic contributions computed for the HOMO of the neutral model compound [8'], suggest that in the corresponding mono-oxidized species the spin density should be equally distributed between the metallic centers, the ethynyl fragments and the aromatic ring. On the other hand, derivative complexes with longer spacers such as $\left(\mu-\mathrm{C} \equiv \mathrm{C}-\left(2,5-\mathrm{SC}_{4} \mathrm{H}_{2}\right)-(\mathrm{C} \equiv \mathrm{C})_{x}-\left(2,5-\mathrm{SC}_{4} \mathrm{H}_{2}\right)-\mathrm{C} \equiv \mathrm{C}\right)(x=1,2)$ belong to the localized Class-II MV compounds. ${ }^{114}$

Recently, the monocationic complexes $\left[\mathrm{M}(\mathrm{dpp}) \mathrm{Cp}^{*}\right]_{2}\left(\mu-\mathrm{C} \equiv \mathrm{C}-\left(2,5-\mathrm{SC}_{4} \mathrm{H}_{2}\right)-\mathrm{C} \equiv \mathrm{C}^{+}\right)(\mathrm{M}=\mathrm{Fe}$, $\mathrm{Ru})$ were investigated both experimentally and theoretically. ${ }^{115}$ As expected, calculations have shown that the spin density is evenly distributed over the metal-bridge-metal backbone. In accordance with the NIR absorption measurements, these strongly delocalized systems were considered as Class-III compounds. However, the presence of two absorption bands in the NIR range, in combination with DFT calculations, have shown that different possible conformers due to the rotation of the organometallic fragments are thermally accessible. The presence of these conformers, with different distributions of the spin density, strongly affects the electronic properties as it will be detailed below (see Section 3.3.2). It is worth mentioning that similar studies were carried out on the corresponding di-ruthenium complexes $\left\{\left[\mathrm{Ru}(\mathrm{dppe}) \mathrm{Cp}^{*}\right]_{2}(\mu-\mathrm{C} \equiv \mathrm{C}-\mathrm{Ar}-\mathrm{C} \equiv \mathrm{C})\right\}^{+}$, with $\mathrm{Ar}=$ $\left(1,4-\mathrm{C}_{6} \mathrm{H}_{4}\right),\left(1,4-\mathrm{C}_{10} \mathrm{H}_{6}\right)$ and $\left(1,4-\mathrm{C}_{14} \mathrm{H}_{8}\right) .{ }^{116,117}$ Similarly to their iron-based analogs, these ruthenium complexes were classified as strongly delocalized Class-III systems, the delocalization of the spin density increasing with the size of the aromatic system. In this case, it is important to remind the reader that such comparisons can only be made for a given choice of functionals and basis set, as the spin density distribution is very sensitive to the choice of these two parameters. ${ }^{118,119}$ 


\subsection{Effect of the topology on the electronic communication}

\subsubsection{The example of meta vs. para-substituted aromatic ring}

Introduction of a para-phenylene moiety into the organic bridge of [5] affords a mono-oxidized specie with valence delocalized properties (see Section 3.2). Experiments have shown that the phenylene unit can also be substituted in the meta and ortho positions. ${ }^{120-122}$ In these cases, two different paths corresponding to the short and long branches of the phenylene unit, can be considered for the electronic coupling between the redox centers. To understand more deeply which branch is involved in the electronic communication, the electronic properties of the model compounds $\left\{[\mathrm{Fe}(\mathrm{dpe}) \mathrm{Cp}]_{2}\left(\mu-\mathrm{C} \equiv \mathrm{C}-\left(1,3-\mathrm{C}_{6} \mathrm{H}_{4}\right)-\mathrm{C} \equiv \mathrm{C}\right)\right\}^{+}\left(\left[\mathbf{9}^{\prime}\right]^{+}\right)$were studied using DFT calculations. ${ }^{120,121}$ In this work, the influence of the insertion of an heteroatom in the phenyl group was also investigated with the study of the complexes $\left\{[\mathrm{Fe}(\mathrm{dpe}) \mathrm{Cp}]_{2}\left(\mu-\mathrm{C} \equiv \mathrm{C}-\left(2,6-\mathrm{NC}_{5} \mathrm{H}_{3}\right)-\mathrm{C} \equiv \mathrm{C}\right)\right\}^{+}$ $\left(\left[\mathbf{1 0}^{\prime}\right]^{+}\right)$and $\left\{[\mathrm{Fe}(\mathrm{dpe}) \mathrm{Cp}]_{2}\left(\mu-\mathrm{C} \equiv \mathrm{C}-\left(3,5-\mathrm{NC}_{5} \mathrm{H}_{3}\right)-\mathrm{C} \equiv \mathrm{C}\right)\right\}^{+}\left([11]^{+}\right) .{ }^{121}$ For each of these three model compounds, different geometrical conformations, corresponding to different orientations of the metallic fragments with respect to each other and with respect to the aromatic ring, were investigated. Symmetrical complexes, denoted $(s)$, correspond to systems where the Cp ligands are on the same side, whereas asymmetrical complexes, denoted (as 1$)$, correspond to systems where one of the $\mathrm{Fe}(\mathrm{dpe}) \mathrm{Cp}$ fragment has been rotated of roughly $90^{\circ}$ along the ethynyl axis. The resulting computed spin densities for $\left[\mathbf{9}^{\prime}\right]^{+},\left[\mathbf{1 0}^{\prime}\right]^{+}$and $\left[\mathbf{1 1}^{\prime}\right]^{+}$are given in Figure 8.

In the symmetrical complexes, the spin density is mainly localized on the two iron centers (ca. $60 \%$ ). However, a sizable part of the spin density is also localized on the ethynyl fragments (ca. $10 \%$ ) and on the aromatic ring (ca. $30 \%$ ), leading to a fully delocalized spin density. The computed atomic spin densities on the aromatic unit are mostly located on atoms of the longest branch, suggesting that the electronic communication between the iron fragments takes place through this pathway and not via the short branch of the aromatic unit. It has to be mentioned that the introduction of a nitrogen atom, either in the short or in the long branch, hardly affects this spin density distribution. Surprisingly enough, the distribution of the spin density is strongly modified for the asymmetrical compounds (see Figure 8). In such systems, the spin density is quasi-exclusively localized on one single iron center (ca. $80 \%$ ) and to a lesser extent on its adjacent ethynyl fragment and on half of the aromatic ring. Consequently, these asymmetrical compounds can be described as valence-trapped systems, with one iron atom being formally in an oxidation state + II and the other one being formally in an oxidation state +III.

The symmetrical and asymmetrical model compounds were found almost iso-energetic (see Figure 8). Therefore, it should be possible that at room temperature these different conformers, with different spin density localization schemes are populated. Experimentally, Mössbauer and EPR spectroscopies carried out on $[\mathbf{9}]^{+},[\mathbf{1 0}]^{+}$and $[\mathbf{1 1}]^{+}$, were characteristic of valence-trapped 


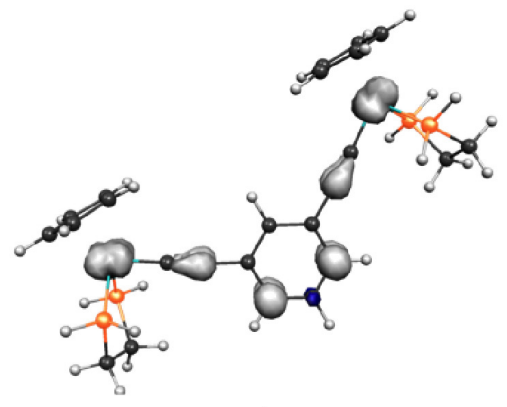

$\left[9^{\prime}\right]^{+} s$

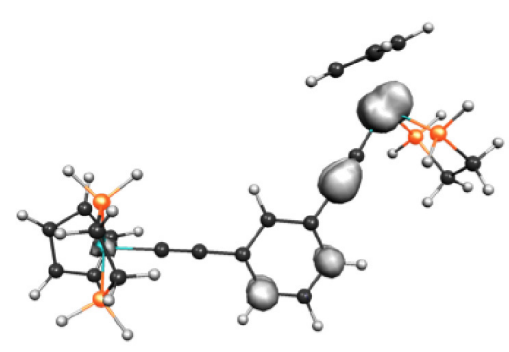

[9' ${ }^{+}$as1

$+0.06 \mathrm{eV}$

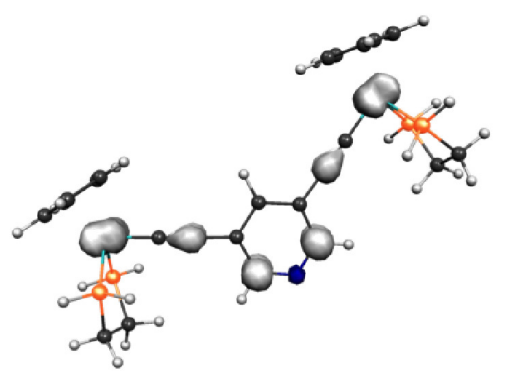

$\left[\mathbf{1 0}^{\prime}\right]^{+} \mathrm{s}$

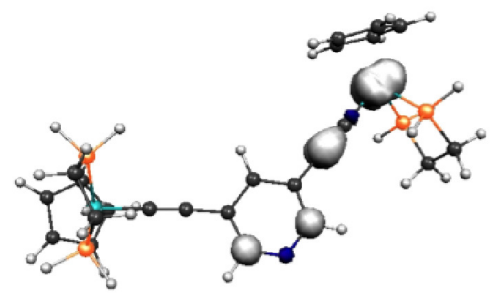

[10'] ${ }^{+}$as 1

$+0.06 \mathrm{eV}$

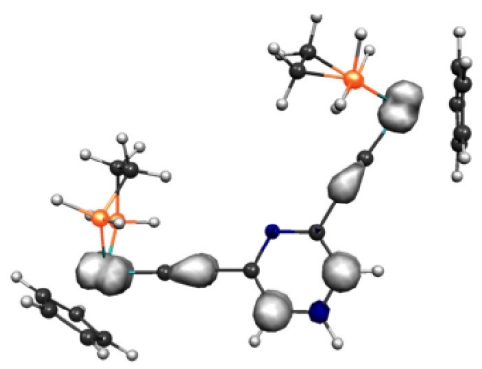

$\left[11^{\prime}\right]^{+} s$

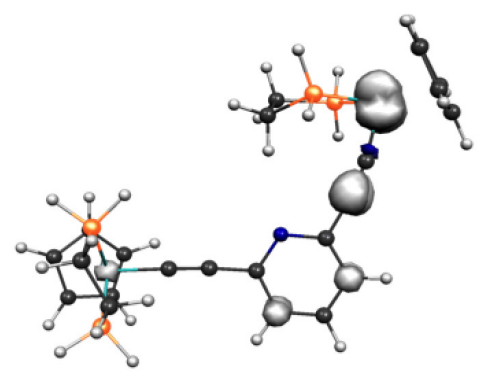

[11'] $]^{+}$as 1 $+0.04 \mathrm{eV}$

Figure 8: DFT contour plots of spin densities in [9' $]^{+},\left[\mathbf{1 0}^{\prime}\right]^{+}$and $\left[\mathbf{1 1}^{\prime}\right]^{+}$for the symmetrical (top) and asymmetrical (bottom) forms. Iso-contour value: \pm 0.004 au. Adapted from Reference [121].

complexes $\left(\mathrm{Fe}^{\mathrm{II}} / \mathrm{Fe}^{\mathrm{III}}\right) .{ }^{121}$ However, the infra-red spectrum of $[\mathbf{1 1}]^{+}$displays three $v(\mathrm{C} \equiv \mathrm{C})$ bands with temperature dependent intensities. This result, in agreement with the computational data, strongly suggests that for $[\mathbf{1 1}]^{+}$, several conformations can coexist in solution, where some of them have their spin density mainly localized on one metallic fragment and the other ones have a delocalized, or pseudo-delocalized, spin density all over the system. The frequencies computed on the related model compound show that probably two asymmetrical conformers should be taken into account in order to explain the trend observed in the IR spectra. On the other hand, complexes $[\mathbf{9}]^{+}$and $[\mathbf{1 0}]^{+}$display only two $v(\mathrm{C} \equiv \mathrm{C})$ bands, assigned to the $\mathrm{Fe}^{\mathrm{II}}-\mathrm{C} \equiv \mathrm{C}$ and $\mathrm{Fe}^{\mathrm{III}}-\mathrm{C} \equiv \mathrm{C}$ stretching modes, which definitely characterizes these systems as localized Class-II mixed-valence complexes $^{121}$

The influence of the meta and para substitution of the aromatic ring on the nature of the electronic coupling were experimentally investigated by scanning tunneling microscopy (STM) for the iron complexes [5] ${ }^{123}$ and [9]. ${ }^{124}$ STM measurements were used here to visualize and probe the charge localization within these Class-II (meta) and Class-III (para) mixed-valence complexes. 


\subsubsection{The role of conformers}

As mentioned in the previous sections, the electronic communication between the metal redox termini in the mixed-valence species can be strongly affected by the presence of rotational conformers. ${ }^{13,128,129}$ Depending on the nature of the organic bridge, three possible sets of conformers can be considered which correspond to (i) rotations of the organic spacer, or (ii) rotations of the metallic fragments or (iii) a combination of both rotations.

The first rotational conformers set arises when the pseudo-cylindrical symmetry of the $(\mathrm{C} \equiv \mathrm{C})_{n}$ bridge is broken by the introduction of a non-cylindrical ligand, such as an aromatic cycle. In this case, different orientations of the aromatic plane, with respect to the plane made by the two

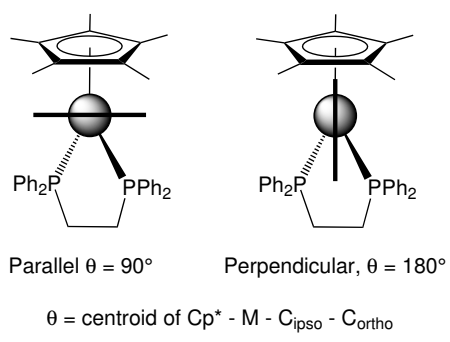

(a)

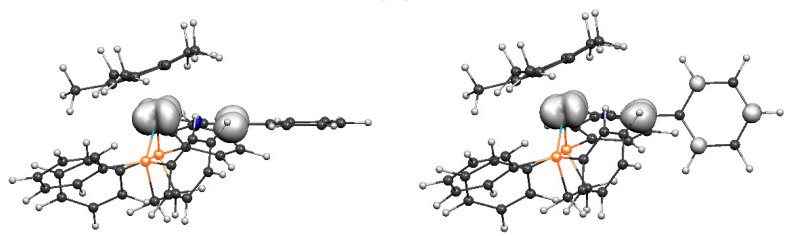

(b)

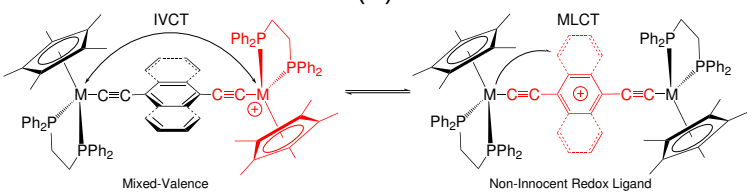

(c)

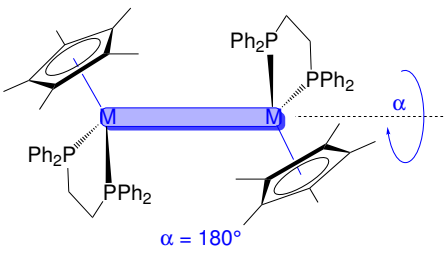

(d)

Figure 9: (a) Torsion angle $\theta$ of the aromatic unit and (b) spin density distributions in [Fe(dppe) $\mathrm{Cp} *$ ] $(\mu-\mathrm{C} \equiv \mathrm{C}-\mathrm{Ph})^{+}$for $\theta=90^{\circ}$ and $180^{\circ}$. Adapted from References [125] and [126]. (c) Charge transfer mechanisms upon ligand rotation. Adapted from Reference [117]. (d) Relative orientation of the metallic termini as a function of the dihedral angle $\alpha$. Adapted from Reference [127]. 
metallic fragments, lead to systems from fully localized mixed-valence complexes to fully bridgedelocalized complexes, as characterized for $\left\{\left[\mathrm{Ru}(\mathrm{dppe}) \mathrm{Cp}^{*}\right]_{2}(\mu-\mathrm{C} \equiv \mathrm{C}-\mathrm{Ar}-\mathrm{C} \equiv \mathrm{C})\right\}^{+}$, with $\mathrm{Ar}=$ $\left(1,4-\mathrm{C}_{6} \mathrm{H}_{4}\right),\left(1,4-\mathrm{C}_{10} \mathrm{H}_{6}\right)$ and $\left(1,4-\mathrm{C}_{14} \mathrm{H}_{8}\right) .{ }^{117}$ The effect of the introduction of an aromatic unit in the carbon ligand has been extensively studied for related monometallic complexes $\left\{\mathrm{MCpL}_{2}\right\}(\mu$ $\mathrm{C} \equiv \mathrm{C})_{n}$-Ph. ${ }^{31,125,126,130,131}$ It has been shown that the phenyl orientation plays an important role in the electron paramagnetic resonance (EPR) spectra, with strong variation of the $g$-factors upon the rotation of the phenyl cycle. ${ }^{126}$ This result was correlated to the changes in the spin density distribution along the arylalkynyl ligand as shown in Figures 9-a and 9-b. For systems where the torsion angle $\theta=180^{\circ}$, the spin density is spread all along the carbon chain and the phenyl group, whereas for the $\theta=90^{\circ}$ conformers, the spin density is heavily concentrated on the $\mathrm{M}-\mathrm{C} \equiv \mathrm{C}$ moiety and hardly on the phenyl ring. Indeed, the delocalization of the spin density onto the aromatic unit is strongly related to the overlap of the $d_{\pi}-\pi$ orbitals of the M-C $\equiv C$ moiety with their related $\pi$ orbitals of the aromatic unit. A similar behavior can occur in the case of bimetallic systems. In $\left\{\left[\mathrm{Ru}(\mathrm{dppe}) \mathrm{Cp}^{*}\right]_{2}(\mu-\mathrm{C} \equiv \mathrm{C}-\mathrm{Ar}-\mathrm{C} \equiv \mathrm{C})\right\}^{+}$, the overlap between the arene $\pi$-framework and the metal frontier orbitals via the alkynyl $\mathrm{C}_{2}$ unit is modified upon the rotation of the aromatic plane, which leads to changes in the distribution of the spin density with the charge localized on either one of the metal centers or localized on the organic bridge. As the bridge and mixed-valence states can be thermally populated, the electronic coupling between the metal termini results in an admixture of metal-to-ligand charge transfer (MLCT) electronic transitions via the bridge-localized state and of inter-valence charge transfer (IVCT) electronic transitions through the mixed-valence states (see Figure 9-c). ${ }^{117}$ A similar behavior was also characterized for the hetero-metallic complex $\left\{\left[\mathrm{Fe}(\mathrm{dppe}) \mathrm{Cp}^{*}\right]\left(\mu-\mathrm{C} \equiv \mathrm{CC}_{6} \mathrm{H} 4 \mathrm{C} \equiv \mathrm{C}\right)\left[\mathrm{Mo}(\mathrm{dppe})\left(\mathrm{C}_{7} \mathrm{H}_{7}\right)\right]\right\}^{+} .{ }^{27}$ DFT calculations on the latter have shown that the spin density distribution can be shifted from one metal to the other one in response to the relative orientation of the arene $\pi$-system and the metal fragments. Such a redox bi-stability was experimentally characterized by IR spectroscopy with the presence of asymmetrical $v(\mathrm{C} \equiv \mathrm{C})$ bands, and by low temperature EPR measurements in which both of the $\left[\mathrm{Fe}(\mathrm{dppe}) \mathrm{Cp}^{*}\right]^{+}$and $\left[\mathrm{Mo}(\mathrm{dppe})\left(\mathrm{C}_{7} \mathrm{H}_{7}\right)\right]^{+}$fragments are visible.

The description of the mixed-valence systems is also affected by conformers arising from the relative orientation of the metal termini (Figure 9-d). As described in Section 3.2, the rotation of one $\left[\mathrm{Fe}(\mathrm{dppe}) \mathrm{Cp}^{*}\right]$ moiety in $[\mathbf{9}]^{+},[\mathbf{1 0}]^{+}$and $[\mathbf{1 1}]^{+}$leads to valence trapped systems which are almost iso-energetic to the fully delocalized systems. ${ }^{12}$ This result makes the usual static interpretation of the spectroscopic data (IR, NIR, EPR) very limited. For instance, the relative orientation of the metallic fragments in the strongly delocalized Class-III complexes $\left[\left\{\mathrm{M}(\mathrm{dppe}) \mathrm{Cp}^{*}\right\}_{2}(\mu\right.$ $\left.\mathrm{C} \equiv \mathrm{C})_{3}\right]^{+}(\mathrm{M}=\mathrm{Fe}, \mathrm{Ru})$ modifies the EPR data. ${ }^{127}$ In this case, the combined experimental and theoretical data have shown that the magnetic anisotropy strongly depends on the conformations of the molecules, with different EPR signals measured for the single crystals and the frozen solu- 
tions. The calculated anisotropies for different values of the dihedral angle $\alpha$ between the metallic fragments (Figure 9-d) have shown that the electronic $g$-factors observed in solution correspond to an average value of the anisotropies of these different conformers, whereas for the single crystal structure the measured anisotropy corresponds to only one conformer. ${ }^{127}$

It is worth mentioning that both ligand and metal fragment rotations can occur in these bimetallic mixed-valence complexes, increasing considerably the degrees of freedom of the molecule and the complexity of the electron-transfer pathway between the redox termini. ${ }^{128}$ In such cases, the usual interpretation of the spectroscopic measurements in term of a two-center model, as well as the localized vs. delocalized picture of the mixed valence system in the Robin and Day classification, might not be appropriate and must be not only based on static description but requires conformational and dynamical studies. ${ }^{129,132}$ The presence of thermally accessible conformers, with different distributions of the spin density, leads to particular experimental features which can only be rationalized by taking into account an admixture of localized and delocalized states. From a computational point of view, the rationalization in solution of the conformers properties necessitates to properly calculate the potential energy surface of the system. This requires a large amount of structural investigation and to take into account the solvent effects, either by using polarizable continuum techniques, such as COSMO or PCM, ${ }^{133-135}$ or by considering directly the solvent molecules in the structural optimizations. To this purpose, Parthey $a l$. have designed an elegant computational strategy to obtain Boltzman-weigthed absorption spectrum of mixed va-

lence complexes. ${ }^{88,129,132}$ In these works, they nicely show that both mixed valence Class-II and Class-III systems can be present in solution depending on the time scale of the observation.

\subsection{Mixed-valence organometallic compounds as candidates for QCAs}

The chemistry of mixed-valence complexes and molecular electronics can join together in the quantum cellular automata (QCA) paradigm. ${ }^{136,137}$ This concept, which has been experimentally demonstrated, ${ }^{138}$ could constitute an attractive alternative to the transistor-based technology, in which binary information is encoded in the configuration of charge among redox-active molecular sites. Indeed, devices in QCAs are constructed from multiple identical cells, with each cell capable of assuming two internal configurations of electrostatic charge. Information is then transmitted and computation can be performed through Coulombic interactions between adjacent cells. ${ }^{139}$ Among potential candidates, mixed-valence organometallic complexes containing two or four metal centers have been proposed as potential single-molecule QCA cells. ${ }^{140-144}$ In principle, if the metal centers have identical electron affinities, the molecule will have two degenerate charge configurations corresponding to different oxidation states on each metal center. Switching between these states would ensure QCA functionality. To this purpose, the asymmetric 


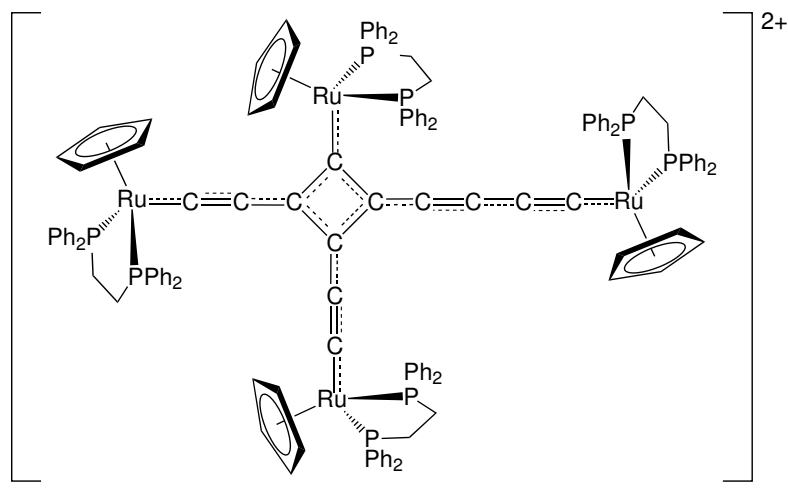

$[12]^{2+}$

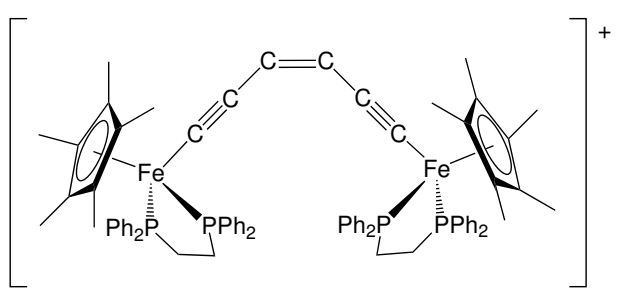

$[13]^{+}$

Figure 10: Examples of candidate QCA molecules.

tetraruthenium dication complex $\{$ cyclo- $\mathrm{C}([\mathrm{Ru}]) \mathrm{C}(\mathrm{CCCC}[\mathrm{Ru})]) \mathrm{C}(\mathrm{CC}[\mathrm{Ru}]) \mathrm{C}(\mathrm{CC}[\mathrm{Ru}])\}^{2+}([\mathrm{Ru}]$ $=\mathrm{Cp}(\mathrm{dppe}) \mathrm{Ru}$, see $[\mathbf{1 2}]^{2+}$ in Figure 10), was prepared from the dimerization of the mixed-valence species $\left[\{\mathrm{Ru}(\mathrm{dppe}) \mathrm{Cp}\}_{2}(\mu-\mathrm{C} \equiv \mathrm{C})_{3}\right]^{+}$and the molecular structure determined. ${ }^{107}$ Unfortunately, both experimental and theoretical DFT results show a fully electron delocalized Class-III mixedvalence species, rendering it probably inappropriate for QCA application. Properties of specific two- and four-dot mixed-valence examples based on hypothetical organometallic molecules containing alkynyl-iron termini such as $\left[\{\mathrm{Cp} *(\mathrm{dppe}) \mathrm{Fe}(\mathrm{C} \equiv \mathrm{C}-)\}_{2}(1,2-\mathrm{C}(\mathrm{H})=\mathrm{C}(\mathrm{H}))\right]^{+}$(see $[\mathbf{1 3}]^{+}$in Figure 10), which better retain the valence-trapped charge on the metal centers have then been theoretically designed and discussed with the aid of DFT calculations. ${ }^{143}$ Results suggest that a valence trapping (Class-II) is observed and that a significant polarization occurs when a biasing charge is added to the systems, satisfying the key requirement for QCA operation.

\section{Two electrons less: toward magnetic species}

The electronic properties of the bimetallic complexes are also interesting when they are doubly oxidized. In these dicationic species, the electronic communication is now defined by the nature of the magnetic coupling that takes place between the two metallic fragments, formally acting as two 
spin-carriers $a$ and $b$. The electronic structure of such systems can be described by three different electronic configurations. A first one corresponds to an open-shell triplet spin-state (T, ferromagnetic coupling), where the two unpaired electrons are formally aligned in a parallel manner. A second spin state consists in a system where the two unpaired electrons are formally aligned in an antiparallel manner, which corresponds to an open-shell singlet state (anti-ferromagnetic coupling). Finally, a closed-shell singlet state (S, diamagnetic), with no unpaired electrons, can also be considered. The magnetic interaction is then assessed with the computation of the magnetic coupling constant $J_{a b}$, which corresponds to the energy difference between the triplet and singlet states based on the following Heisenberg-Dirac-van Vleck Hamiltonian: ${ }^{145-147}$

$$
\hat{H}=-\sum_{a>b} J_{a b} \cdot \hat{S}_{a} \cdot \hat{S}_{b}
$$

Due to its mono-determinantal character, Kohn-Sham DFT performs poorly in reproducing the proper wavefunction of the open-shell singlet state. Indeed, if a triplet state can be described with a single determinant, i.e., $\left|a_{g} a_{u}\right|$ where $a_{g}$ and $a_{u}$ are the molecular orbitals corresponding to the bonding and anti-bonding combinations of the magnetic orbitals of the metallic centers, a similar description cannot be made with an open-shell singlet state. This latter corresponds to a linear combination of two determinants, i.e., $\frac{1}{\sqrt{2}}\left(\left|a_{g} \bar{a}_{u}\right|-\left|\bar{a}_{g} a_{u}\right|\right) .{ }^{148,149}$ The energy of such an open-shell singlet state is therefore calculated using the broken symmetry (BS) approach developed by L. Noodleman. ${ }^{150}$ The BS wavefunction represents a state of mixed spin with an energy $E_{B S}=\frac{1}{2}\left(E_{S}+\right.$ $\left.E_{T}\right) .{ }^{151}$ Consequently, the BS state cannot be considered as a pure singlet spin state $\left(\left\langle S^{2}\right\rangle=0\right)$ and contains strong spin contamination arising from admixture with the triplet wavefunction. Using the DFT BS and triplet energies, it becomes then possible to estimate the magnetic interaction as:

$$
J_{a b}=2\left(E_{B S}-E_{T}\right)
$$

However, due to the large spin contamination in the BS solution, evaluation of $J_{a b}$ is subject to controversy and several methodologies can be found in the literature. ${ }^{152-156}$ A commonly used approach is the following spin-projected formula:

$$
J_{a b}=2\left[E_{B S}-E_{T}\right] /\left[\left\langle S^{2}\right\rangle_{T}-\left\langle S^{2}\right\rangle_{B S}\right]
$$

where $\left\langle S^{2}\right\rangle_{B S}$ and $\left\langle S^{2}\right\rangle_{T}$ correspond to the calculated square of the spin operator for both spin states, and equal to ca. 1 and 2 for systems containing two unpaired electrons. For a sake of clarity, the magnetic coupling constants $J$ discussed in the following were obtained with Equation 3 which allows to reduce the spin contamination of the BS states. 


\subsection{Nature of the Magnetic Coupling in the $\left[\left\{\mathrm{MCpL}_{2}\right\}_{2}(\mu-\mathrm{C} \equiv \mathrm{C})_{2}\right]^{2+}$ Series}

Magnetic susceptibility measurements carried out in solution on the di-iron complex $[1]^{2+}$ have revealed a small antiferromagnetic coupling, characterized by a $J_{\exp }$ value of $-18 \mathrm{~cm}^{-1}{ }^{77}$ However, as the temperature increases, a paramagnetic character was also observed, suggesting that both singlet and triplet states are close in energy and should be present simultaneously in solution. On the other hand, the singlet state is strongly favored for the hetero-bimetallic complex $\left[\left\{\mathrm{Fe}(\mathrm{dppe}) \mathrm{Cp}^{*}\right\}(\mu-\mathrm{C} \equiv \mathrm{C})_{2}\left\{\mathrm{Ru}(\mathrm{dppe}) \mathrm{Cp}^{*}\right\}\right]^{2+}$. Indeed, for this latter a magnetic coupling constant of $-500 \mathrm{~cm}^{-1}$ was measured, ${ }^{77}$ which is clearly characteristic of a strong antiferromagnetic coupling between both metallic fragments. This antiferromagnetic behavior is even increased in the di-ruthenium compound $[2]^{2+}\left(J_{\text {exp }} \approx-850 \mathrm{~cm}^{-1}\right)$, suggesting that the use of the Ru fragments stabilizes the singlet state. The magnetic properties of these complexes were tentatively rationalized with a DFT study of the corresponding model compounds $\left[\{\mathrm{M}(\mathrm{dpe}) \mathrm{Cp}\}_{2}(\mu-\mathrm{C} \equiv \mathrm{C})_{2}\right]^{2+} .{ }^{77} \operatorname{In}\left[\mathbf{1}^{\prime}\right]^{2+}$, the singlet (closed-shell) and the triplet spin-states were computed to be quasi iso-energetic leading to almost null theoretical $J$ value. In agreement with the experimental data, the closed-shell singlet state is found more stable of ca. $0.13 \mathrm{eV}$ than the triplet state in [2' $]^{2+}$. By contrast, for the heterometallic model system $\left[\{\mathrm{Fe}(\mathrm{dpe}) \mathrm{Cp}\}(\mu-\mathrm{C} \equiv \mathrm{C})_{2}\{\mathrm{Ru}(\mathrm{dpe}) \mathrm{Cp}\}\right]^{2+}$, the singlet state is slightly favored by $0.04 \mathrm{eV}$ over the triplet state, which do not reflects the strong antiferromagnetic coupling observed experimentally. It has to be noticed that the open-shell singlet states were not taken into account in these studies, ${ }^{77}$ and consequently these results must be taken with caution. Nevertheless, it was clearly evidenced that the stability of the closed-shell singlet state, with respect to the triplet state, must be related to the HOMO-LUMO energy gap of the singlet system. Indeed, an increase of this HOMO-LUMO energy gap was computed in the $\left[\{\mathrm{M}(\mathrm{dpe}) \mathrm{Cp}\}_{2}(\mu-\mathrm{C} \equiv \mathrm{C})_{2}\right]^{2+}$ series when the iron fragments are successively replaced by one and then two ruthenium fragments, increasing the antiferromagnetic behavior of these systems.

\subsection{Modulation of the magnetic coupling in $\left[\left\{\mathrm{Fe}(\text { dppe }) \mathrm{Cp}^{*}\right\}_{2}(\mu-\mathrm{C} \equiv \mathrm{C})_{3}\right]^{2+}$}

As previously described in the case of the mixed-valence species (see Section 3.3.2), the magnetic behavior of the dicationic bimetallic complexes of general formula $\left[\left\{\mathrm{MCpL}_{2}\right\}_{2}(\mu-\mathrm{C} \equiv \mathrm{C})_{n}\right]^{2+}$ can be modulated by the relative orientation of the metal centers. For instance, combined experimental and theoretical investigations performed on $\left[\left\{\mathrm{Fe}(\mathrm{dppe}) \mathrm{Cp}^{*}\right\}_{2}(\mu-\mathrm{C} \equiv \mathrm{C})_{3}\right]^{2+}\left([4]^{2+}\right)$ have shown that depending on the relative orientation of the two spin carriers, a strong antiferromagnetic coupling or a small ferromagnetic coupling can be characterized between the metal termini. ${ }^{127}$ Indeed, the magnetic susceptibility measurements performed on a single crystal of $[4]^{2+}$ were found characteristic of a strong antiferromagnetic coupling between the two spin carriers with $J_{\text {exp }}$ larger than $-600 \mathrm{~cm}^{-1}$. However, a constant $\chi_{M} T=0.4 \mathrm{~cm}^{3} \mathrm{~K} \mathrm{~mol}^{-1}$ was characterized when the magnetic 


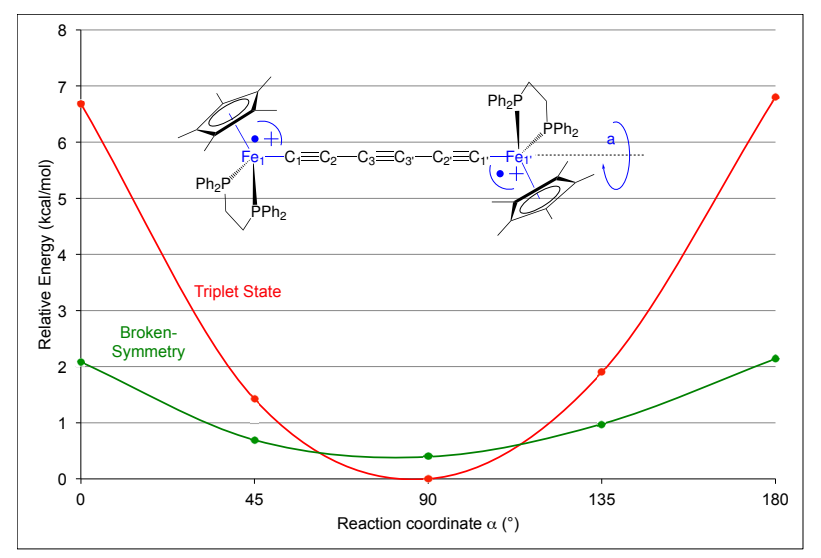

Figure 11: Relative total energy variation $(\mathrm{kcal} / \mathrm{mol})$ as a function of the dihedral angle $\alpha$ for the triplet and BS states of [4] $]^{2+}$. Adapted from Reference [127].

susceptibility measurements were performed on dissolved single crystals. Such a value of $\chi_{M} T$ corresponds to an intermediate value between expected values for (i) a diamagnetic ground state $(S=0)$, (ii) a ferromagnetic ground state $(S=1)$ and (iii) a paramagnetic ground state with two non-interacting spins. This magnetic behavior was attributed to the presence in solution of a distribution of different conformers with different magnetic ground states.

The magnetic behavior of $[4]^{2+}$ was rationalized with the help of a conformational study performed at the DFT level. As seen in Figure 11, for symmetrical systems, i.e., complexes with $\mathrm{Cp}^{*}$ (centroid)-Fe-Fe-Cp*(centroid) dihedral angle $\alpha$ of $0^{\circ}$ or $180^{\circ}$, the open-shell singlet state (BS solution) is strongly favored over the triplet state. For these conformations, an antiferromagnetic coupling constant $J$ of $-1414 \mathrm{~cm}^{-1}$ was computed, which is in relatively good agreement with the large experimental value $J_{\text {exp }}=-600 \mathrm{~cm}^{-1}$ measured on a single crystal $\left(\alpha=180^{\circ}\right)$. Interestingly, the rotation of one of the $\mathrm{Fe}(\mathrm{dppe}) \mathrm{Cp}^{*}$ moiety with respect to the other one leads to a stronger energetic stabilization of the triplet state compared to the BS solution. In the particular case of $\alpha=90^{\circ}$, the triplet state becomes even energetically favored compared to the BS state, leading to a calculated ferromagnetic coupling constant $J$ of $+140 \mathrm{~cm}^{-1}$.

The magnetic behavior of $[4]^{2+}$ with the relative orientation of the metal fragments can be rationalized with the calculated atomic spin densities for the different conformations (see Table 2). For the antiferromagnetic states, the rotation of one metallic fragment with respect to the other one from $\alpha=90^{\circ}$ to $0^{\circ}$ leads to a slight decrease of the spin-polarization on the carbon bridge. Similar rotation of the metallic fragment in the ferromagnetic states strongly reduces the delocalization of the spin density on the carbon spacer. The presence in the carbon bridge of an atom having no spin density probably switches off the magnetic coupling between the two metallic termini, and thus strongly destabilized this system. Clearly, the magnetic coupling between the redox centers 
Table 2: Calculated Atomic Spin Densities (e) for Selected Rotamers of [4] ${ }^{2+}$.

\begin{tabular}{lccccccccc}
\hline Complexes & & $\mathrm{Fe}_{1}$ & $\mathrm{C}_{1}$ & $\mathrm{C}_{2}$ & $\mathrm{C}_{3}$ & $\mathrm{C}_{3}^{\prime}$ & $\mathrm{C}_{2}^{\prime}$ & $\mathrm{C}_{1}^{\prime}$ & $\mathrm{Fe}_{1}^{\prime}$ \\
\hline$\alpha=0^{\circ}$ & $\mathrm{BS}$ & 0.936 & -0.320 & 0.264 & -0.267 & 0.267 & -0.264 & 0.320 & 0.936 \\
& $\mathrm{~T}$ & 1.004 & 0.000 & 0.142 & 0.072 & 0.059 & 0.154 & -0.018 & 0.975 \\
$\alpha=45^{\circ}$ & $\mathrm{BS}$ & 0.931 & -0.336 & 0.273 & -0.280 & 0.280 & -0.272 & 0.333 & -0.930 \\
& $\mathrm{~T}$ & 0.979 & -0.022 & 0.157 & 0.063 & 0.067 & 0.154 & -0.016 & 0.992 \\
$\alpha=90^{\circ}$ & $\mathrm{BS}$ & 0.934 & -0.344 & 0.278 & -0.288 & 0.288 & -0.278 & 0.343 & -0.932 \\
& $\mathrm{~T}$ & 0.986 & -0.023 & 0.156 & 0.064 & 0.065 & 0.155 & -0.022 & 0.987 \\
\hline
\end{tabular}

BS: Broken Symmetry, T: Triplet state.

is controlled by the torsion angle between the terminal spin carriers, which allows the inversion of the BS state over the triplet ground state. It has to be mentioned that such a behavior has been also seen theoretically observed for the related complex $\left.\left\{\mathrm{Mn}(\mathrm{dHpe})\left(\mathrm{MeC}_{5} \mathrm{H}_{4}\right)\right\}_{2}(\mu-\mathrm{C} \equiv \mathrm{C})_{2}\right] .{ }^{157}$

\subsection{Magnetic interactions with an aromatic ring inserted in the carbon spacer}

The effect of the introduction of an aromatic ring into the poly-yne chain on the magnetic properties of the $\left\{\left[\mathrm{Fe}(\mathrm{dppe}) \mathrm{Cp}^{*}\right]_{2}(\mu-\mathrm{C} \equiv \mathrm{C}-\mathrm{Ar}-\mathrm{C} \equiv \mathrm{C}\}^{2+}\right.$ complexes, were also investigated both experimentally and theoretically. ${ }^{158}$ As we have seen previously for the related mixed-valence complexes, introduction of an aromatic unit on the organic bridge stabilizes the oxidized species. However, according to the nature of the aromatic cycle, the electronic communication between the metallic termini can be drastically altered. The magnetic susceptibilities measurements carried out on $[5]^{2+},[6]^{2+}$ and $[9]^{2+}$ have revealed differences in the nature of the magnetic coupling in these systems depending on the nature of the aromatic ring. Introduction of a para-phenylene unit inside the carbon spacer leads to a strong antiferromagnetic coupling between the $\mathrm{Fe}(\mathrm{dppe}) \mathrm{Cp}^{*}$ fragments. This strong antiferromagnetic interaction is characterized by a $J_{\text {exp }}$ value of $-190 \mathrm{~cm}^{-1}$, significantly larger compared to the related system $[1]^{2+}\left(J_{\text {exp }}=-18 \mathrm{~cm}^{-1}\right)$, described previously. Surprisingly enough, when a meta-phenylene group is inserted into the bridge $\left([9]^{2+}\right)$, the nature of the magnetic coupling between the two iron-based metallic fragments is strongly modified and a ferromagnetic interaction $\left(J_{\exp }=+150 \mathrm{~cm}^{-1}\right)$ was evidenced in this case. Finally, with the addition of a second para-phenylene unit in complex $[6]^{2+}$, a much weaker antiferromagnetic coupling $\left(J_{\exp } \approx-1 \mathrm{~cm}^{-1}\right)$ was observed, suggesting a small energy gap between both singlet and triplet states.

The magnetic properties of these systems were rationalized with the help of theoretical calculations carried out on the model compounds. ${ }^{158}$ For all of them, both the closed-shell singlet, the open-shell singlet and the triplet spin configurations were optimized in order to theoretically estimate the nature the magnetic interactions taking place in these complexes. It turns out that the closed-shell singlet systems were systematically found less stable by over $1 \mathrm{eV}$ than the corre- 

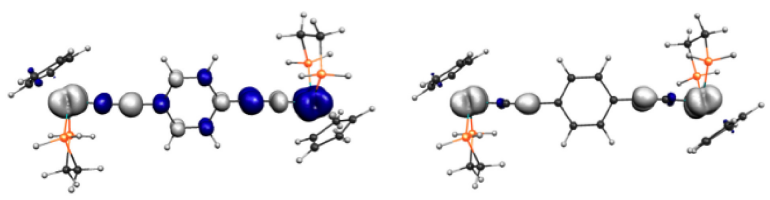

BS

$\left[5^{3}\right]^{2+}$

Triplet

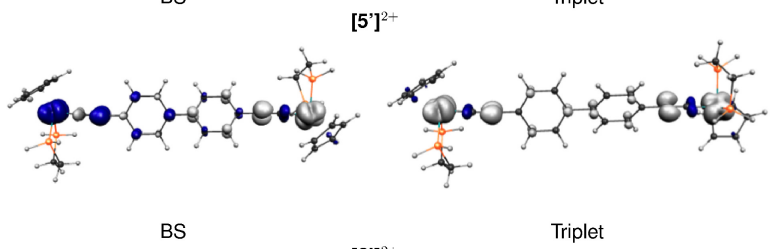

$\left[6^{\prime}\right]^{2}$

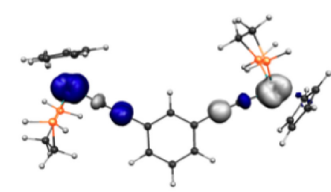

BS

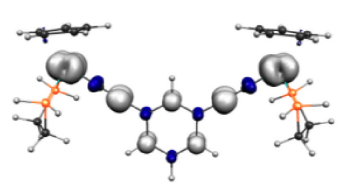

$\left[9^{\prime}\right]^{2+}$

Triplet

Figure 12: DFT contour plots of the computed spin densities for the BS and triplet states of the model compounds $\left[\mathbf{5}^{\prime}\right]^{2+},\left[\mathbf{6}^{\prime}\right]^{2+}$ and $\left[\mathbf{9}^{\prime}\right]^{2+}$. Iso-contour value: $\pm 0.005 \mathrm{au}$.

sponding open-shell systems and consequently, they will not be discussed thereafter. The magnetic coupling constants computed for these model compounds match fairly well with the experimental data. In $\left[\mathbf{5}^{\prime}\right]^{2+}$, the BS solution is energetically favored compared to the triplet system, leading to a calculated $J_{\text {calc }}$ value of $-255 \mathrm{~cm}^{-1}$, characteristic of a strong antiferromagnetic coupling. In agreement with the experimental data, complex $\left[\mathbf{9}^{\prime}\right]^{2+}$ is computed with a strong ferromagnetic behavior $\left(J_{\text {calc }}=+256 \mathrm{~cm}^{-1}\right)$, the triplet state lying at lower energy than the open-shell singlet system. The BS-triplet energy gap strongly decreases in [6' $]^{2+}$. However, the BS state remains energetically favored which leads to an antiferromagnetic interaction between the metallic termini. The computed $J_{\text {calc }}$ value of $-79 \mathrm{~cm}^{-1}$ qualitatively reproduces the decrease of the magnetic coupling, but largely overestimates the experimental value $\left(J_{\exp } \approx-1 \mathrm{~cm}^{-1}\right)$.

These different magnetic behaviors for these three compounds were rationalized using their spin density distributions. The spatial distributions of the spin density obtained for $\left[\mathbf{5}^{\prime}\right]^{2+},\left[\mathbf{6}^{\prime}\right]^{2+}$ and $\left[\mathbf{9}^{\prime}\right]^{2+}$, in their BS and triplet states are given in Figure 12. Qualitatively, the stabilization of the BS state over the triplet one can be rationalized by a larger delocalization and a stronger polarization of the spin density on the organic bridge. In [5' $]^{2+}$, the spin density of the triplet state is strongly located on the metallic fragments. No sizable atomic spin densities are found on the aromatic ring. For the related $\mathrm{BS}$ state, the spin density is instead delocalized all over the Fe- $\mathrm{C}_{2}$ Ar- $\mathrm{C}_{2}-\mathrm{Fe}$ backbone, with an alternation of positive and negative atomic spin densities, stabilizing this BS solution by spin polarization. Upon introduction of a meta-substituted phenylene unit 
into the poly-yne chain $\left(\left[\mathbf{9}^{\prime}\right]^{2+}\right)$, both delocalization and polarization of the spin density along the carbon spacer are broken for the open-shell singlet system. By contrast, such a delocalization of the spin density is observed in the triplet state, promoting thus a ferromagnetic coupling for this compound. In the case of [6' $]^{2+}$, containing two para-phenylene groups, the different orientations of the phenyl rings with respect to each other, leads to a decrease of both the spin delocalization and spin polarization onto the organic bridge, leading to a small BS-triplet energy gap and a strong decrease of the antiferromagnetic coupling.

Influence of the presence of a heteroatom in the aromatic bridge was also investigated in $[\mathbf{1 0}]^{2+}$ and $[\mathbf{1 1}]^{2+} .^{121}$ Magnetic susceptibility measurements revealed that the magnetic properties of these complexes, are strongly altered depending on the position of the nitrogen atom. Indeed in $[\mathbf{1 1}]^{2+}$, where the nitrogen atom is inserted in the short branch of the aromatic ring, a small ferromagnetic interaction ( $J_{\exp }=+2 \mathrm{~cm}^{-1}$ ) was characterized between the two metallic fragments $\mathrm{Fe}(\mathrm{dppe}) \mathrm{Cp}^{*}$, whereas a much larger ferromagnetic coupling $\left(J_{\exp }>500 \mathrm{~cm}^{-1}\right)$ was observed in $[10]^{2+}$, where the $\mathrm{N}$ atom is located on the long branch. Furthermore, the theoretical study performed on the model compound $\left[\mathbf{1 0}^{\text {' }}\right]^{2+}$ has shown that the orientation of the metallic fragments $\mathrm{Fe}(\mathrm{dpe}) \mathrm{Cp}$ with respect to each other, can strongly influence the magnetic communication in these systems. Indeed, for two different conformations, the computed $J_{\text {calc }}$ for the model compound $\left[\mathbf{1 0}^{\prime}\right]^{2+}$ ranged from 91 to $589 \mathrm{~cm}^{-1}$ depending on the conformer used in the calculations. ${ }^{121}$

\section{Conclusions and outlook}

During the three last decades, experimental chemists have forged quite a large variety of bimetallic complexes in which two redox-active metal end-cap groups are linked by a carbon-rich bridge. Their extensive redox chemistry with multiple, stepwise, one-electron oxidation processes provide them some interesting electronic and/or magnetic properties for potential applications. Examples discussed in this review have illustrated how theoretical quantum chemical computations have greatly assisted the development of this field of research. In synergy with experiments, computational results can provide additional valuable information about (i) the nature of the localized vs. delocalized electronic communication in the mono-oxidized mixed-valence species, or (ii) the magnetic coupling differences and characteristics of the di-oxidized complexes. They can also provide further opportunities to explore how conformational effects may affect these properties. There is no doubt that this organometallic wire chemistry remains a fertile ground of investigation that continues to present challenges to not only experiments, but also to theory such as the dynamics associated with the intramolecular electron transfer in mixed-valence systems. ${ }^{159,160}$ Resolution of these challenges will provide important insight into our understanding of the bonding and properties of these molecules for their application in molecular electronics. 


\section{Acknowledgments}

All current and former group members, in particular S. Kahlal, G. Frapper, H. Jiao, K. Costuas, S. Messaoudi, S. Fathallah, N. Ouddai, A. Ladjarafi, T. Davin, and H. Sahnoune, as well colleagues and friends who have been involved in numerous and fruitful collaborations and discussions over many years, in particular C. Lapinte, F. Paul, and J.-R. Hamon (Rennes), M. I. Bruce and N. N. Zaitseva (Adelaide), P. J. Low (Perth), J. A. Gladysz (College Station), V. W.-W. Yam (Hong Kong), and M. W. Whiteley (Manchester) are warmly acknowledged.

\section{References}

[1] H. Lang, Angew. Chem. Int. Ed. 1994, 33, 547-550.

[2] F. Paul, C. Lapinte, Coord. Chem. Rev. 1998, 178-180, 431-509.

[3] F. Paul, C. Lapinte Magnetic Communication in Binuclear Organometallic Complexes Mediated by Carbon-Rich Bridges in Unusual Structures and Physical Properties in Organometallic Chemistry, M. Giellen, R. Willem, B. Wrackmeyer (Eds.), Wiley, London, 2002, chapter 6, pp. 220-291.

[4] S. Szafert, J. A. Gladysz, Chem. Rev. 2003, 103, 4175-4206.

[5] S. Szafert, J. A. Gladysz, Chem. Rev. 2006, 106, PR1-PR33.

[6] N. J. Long, C. K. Williams, Angew. Chem. Int. Ed. 2003, 42, 2586-2617.

[7] M. I. Bruce, P. J. Low, Transition Metal Complexes Containing All-Carbon Ligands, Vol. 50, Academic Press, 2004, pp. 179-444.

[8] M. I. Bruce, Coord. Chem. Rev. 2004, 248, 1603-1625.

[9] T. Ren, Organometallics 2005, 24, 4854-4870.

[10] P. J. Low, R. L. Roberts, R. L. Cordiner, F. Hartl, J. Solid State Electrochem. 2005, 9, $717-731$.

[11] M. Akita, T. Koike, Dalton Trans. 2008, 3532-3530.

[12] K. Costuas, S. Rigaut, Dalton Trans. 2011, 40, 5643-5658.

[13] P. J. Low, Coord. Chem. Rev. 2013, 257, 1507-1532. 
[14] J.-F. Halet, C. Lapinte, Coord. Chem. Rev. 2013, 257, 1584-1613.

[15] Y.-W. Zhong, Z.-L. Gong, J.-Y. Shao, J. Yao, Coord. Chem. Rev. 2016, 312, 22-40.

[16] J.-M. Lehn, Suparmolecular Chemistry: Concepts and Perspectives, VCH, Weinheim, Germany, 1995.

[17] A. F. Hill, R. A. Manzano, Angew. Chem. Int. Ed. 2019, 58, 15354-15357.

[18] C. Egler-Lucas, O. Blacque, K. Venkatesan, A. López-Hernández, H. Berke, Eur. J. Inorg. Chem. 2012, 2012, 1536-1545.

[19] S. Kheradmandan, K. Heinze, H. W. Schmalle, H. Berke, Angew. Chem. Int. Ed. 1999, 38, 2270-2273.

[20] K. Venkatesan, O. Blacque, H. Berke, Dalton Trans. 2007, 1091-1100.

[21] A. Sakurai, M. Akita, Y. Moro-oka, Organometallics 1999, 18, 3241-3244.

[22] W. A. Hoffert, A. K. Rappé, M. P. Shores, J. Am. Chem. Soc. 2011, 133, 20823-20836.

[23] F. Lissel, F. Schwarz, O. Blacque, H. Riel, E. Lörtscher, K. Venkatesan, H. Berke, J. Am. Chem. Soc. 2014, 136, 14560-14569.

[24] L. Medei, L. Orian, O. V. Semeikin, M. G. Peterleitner, N. A. Ustynyuk, S. Santi, C. Durante, A. Ricci, C. Lo Sterzo, Eur. J. Inorg. Chem. 2006, 2006, 2582-2597.

[25] T. D. Cook, P. E. Fanwick, T. Ren, Organometallics 2014, 33, 4621-4624.

[26] B. Le Guennic, K. Costuas, J.-F. Halet, C. Nervi, M. A. J. Paterson, M. A. Fox, R. L. Roberts, D. Albesa-Jove, H. Puschmann, J. A. K. Howard, P. J. Low, C. R. Chimie 2005, 8, 1883-1896.

[27] E. C. Fitzgerald, A. Ladjarafi, N. J. Brown, D. Collison, K. Costuas, R. Edge, J.-F. Halet, F. Justaud, P. J. Low, H. Meghezzi, T. Roisnel, M. W. Whiteley, C. Lapinte, Organometallics 2011, 30, 4180-4195.

[28] E. C. Fitzgerald, N. J. Brown, R. Edge, M. Helliwell, H. N. Roberts, F. Tuna, A. Beeby, D. Collison, P. J. Low, M. W. Whiteley, Organometallics 2012, 31, 157-169.

[29] A. Klein, O. Lavastre, J. Fiedler, Organometallics 2006, 25, 635-643.

[30] C. Olivier, B. Kim, D. Touchard, S. Rigaut, Organometallics 2008, 27, 509-518. 
[31] S. Marqués-González, M. Parthey, D. S. Yufit, J. A. K. Howard, M. Kaupp, P. J. Low, Organometallics 2014, 33, 4947-4963.

[32] J. Zhang, M.-X. Zhang, C.-F. Sun, M. Xu, F. Hartl, J. Yin, G.-A. Yu, L. Rao, S. H. Liu, Organometallics 2015, 34, 3967-3978.

[33] J. Zhang, Y. Ou, M. Xu, C. Sun, J. Yin, G.-A. Yu, S. H. Liu, Eur. J. Inorg. Chem. 2014, 2014, 2941-2951.

[34] G.-L. Xu, G. Zou, Y.-H. Ni, M. C. DeRosa, R. J. Crutchley, T. Ren, J. Am. Chem. Soc. 2003, 125, 10057-10065.

[35] Z. Cao, B. Xi, D. S. Jodoin, L. Zhang, S. P. Cummings, Y. Gao, S. F. Tyler, P. E. Fanwick, R. J. Crutchley, T. Ren, J. Am. Chem. Soc. 2014, 136, 12174-12183.

[36] M. A. Fox, J. D. Farmer, R. L. Roberts, M. G. Humphrey, P. J. Low, Organometallics 2009, 28, 5266-5269.

[37] D.-B. Zhang, J.-Y. Wang, H.-M. Wen, Z.-N. Chen, Organometallics 2014, 33, 4738-4746.

[38] M. A. Fox, R. L. Roberts, T. E. Baines, B. Le Guennic, J.-F. Halet, F. Hartl, D. S. Yufit, D. Albesa-Jové, J. A. K. Howard, P. J. Low, J. Am. Chem. Soc. 2008, 130, 3566-3578.

[39] M. I. Bruce, J.-F. Halet, B. Le Guennic, B. W. Skelton, M. E. Smith, A. H. White, Inorg. Chim. Acta 2003, 350, 175-181.

[40] M. I. Bruce, B. Le Guennic, N. Scoleri, N. N. Zaitseva, J.-F. Halet, Organometallics 2012, 31, 4701-4706.

[41] M. I. Bruce, B. G. Ellis, J.-F. Halet, B. Le Guennic, B. K. Nicholson, H. Sahnoune, N. Scoleri, B. W. Skelton, A. N. sobolev, C. J. Sumby, A. H. White, N. N. Zaitseva, Inorg. Chim. Acta 2016, 453, 654-666.

[42] R. D. Dewhurst, A. F. Hill, A. C. Willis, Organometallics 2004, 23, 1646-1648.

[43] J. Sun, S. E. Shaner, M. K. Jones, D. C. O’Hanlon, J. S. Mugridge, M. D. Hopkins, Inorg. Chem. 2010, 49, 1687-1698.

[44] S. N. Semenov, O. Blacque, T. Fox, K. Venkatesan, H. Berke, J. Am. Chem. Soc. 2010, 132, 3115-3127.

[45] W. Weng, T. Bartik, M. Brady, B. Bartik, J. A. Ramsden, A. M. Arif, J. A. Gladysz, J. Am. Chem. Soc. 1995, 117, 11922-11931. 
[46] R. Dembinski, T. Bartik, B. Bartik, M. Jaeger, J. A. Gladysz, J. Am. Chem. Soc. 2000, 122, 810-822.

[47] S. C.-F. Lam, V. W.-W. Yam, K. M.-C. Wong, E. C.-C. Cheng, N. Zhu, Organometallics 2005, 24, 4298-4305.

[48] R. D. Young, A. F. Hill, G. E. Cavigliasso, R. Stranger, Angew. Chem. Int. Ed. 2013, 52, 3699-3702.

[49] M. I. Bruce, K. Kramarczuk, B. W. Skelton, A. H. White, J. Organomet. Chem. 2010, 695, 469-473.

[50] M. Janka, G. K. Anderson, N. P. Rath, Organometallics 2004, 23, 4382-4390.

[51] Q. Zheng, J. A. Gladysz, J. Am. Chem. Soc. 2005, 127, 10508-10509.

[52] X. Zhao, T. Cardolaccia, R. T. Farley, K. A. Abboud, K. S. Schanze, Inorg. Chem. 2005, 44, 2619-2627.

[53] V. W.-W. Yam, K. M.-C. Wong, N. Zhu, Angew. Chem. Int. Ed. 2003, 42, 1400-1403.

[54] G. R. Owen, J. Stahl, F. Hampel, J. A. Gladysz, Chem. Eur. J. 2008, 14, 73-87.

[55] R. D. Dewhurst, A. F. Hill, M. K. Smith, Organometallics 2005, 24, 5576-5580.

[56] M.-C. Oerthel, D. S. Yufit, M. A. Fox, M. R. Bryce, P. J. Low, Organometallics 2015, 34, 2395-2405.

[57] M. J. Bartlett, A. F. Hill, M. K. Smith, Organometallics 2005, 24, 5795-5798.

[58] F. Paul, W. E. Meyer, L. Toupet, H. Jiao, J. A. Gladysz, C. Lapinte, J. Am. Chem. Soc. 2000, $122,9405-9414$.

[59] X. Wang, X. You, Z.-P. Shang, J. Xia, J. Organomet. Chem. 2016, 803, 111-118.

[60] A. Gunay, W. W. Brennessel, W. D. Jones, Organometallics 2015, 34, 2233-2239.

[61] M. Linseis, S. Záliš, M. Zabel, R. F. Winter, J. Am. Chem. Soc. 2012, 134, 16671-16692.

[62] W. Mohr, J. Stahl, F. Hampel, J. A. Gladysz, Chem. Eur. J. 2003, 9, 3324-3340.

[63] Y.-P. Ou, J. Zhang, M.-X. Zhang, F. Zhang, D. Kuang, F. Hartl, S. H. Liu, Inorg. Chem. 2017, 56, 11074-11086. 
[64] K. Sugimoto, H. Idei, Y. Tanaka, M. Akita, J. Organomet. Chem. 2017, 847, 121-131.

[65] A. Miyazaki, Y. Ogyu, F. Justaud, L. Ouahab, T. Cauchy, J.-F. Halet, C. Lapinte, Organometallics 2010, 29, 4628-4638.

[66] A. Burgun, F. Gendron, T. Roisnel, S. Sinbandhit, K. Costuas, J.-F. Halet, M. I. Bruce, C. Lapinte, Organometallics 2013, 32, 1866-1875.

[67] F. Justaud, F. Gendron, Y. Ogyu, Y. Kumamoto, A. Miyazaki, L. Ouahab, K. Costuas, J.-F. Halet, C. Lapinte, Chem. Eur. J. 2013, 19, 5742-5757.

[68] R. Makhoul, Y. Kumamoto, A. Miyazaki, F. Justaud, F. Gendron, J.-F. Halet, J.-R. Hamon, C. Lapinte, Eur. J. Inorg. Chem. 2014, 2014, 3899-3911.

[69] R. Makhoul, J. B. G. Gluyas, K. B. Vincent, H. Sahnoune, J.-F. Halet, P. J. Low, J.-R. Hamon, C. Lapinte, Organometallics 2018, 37, 4156-4171.

[70] H. Sahnoune, V. Mahias, J.-F. Halet, C. Lapinte, Organometallics 2019, 38, 2724-2737.

[71] T. Weyland, C. Lapinte, G. Frapper, M. J. Calhorda, J.-F. Halet, L. Toupet, Organometallics 1997, 16, 2024-2031.

[72] T. Weyland, K. Costuas, A. Mari, J.-F. Halet, C. Lapinte, Organometallics 1998, 17, 55695579.

[73] K. M.-C. Wong, S. C.-F. Lam, C.-C. Ko, N. Zhu, S. Roué, C. Lapinte, S. Fathallah, K. Costuas, S. Kahlal, J.-F. Halet, Inorg. Chem. 2003, 42, 7086-7097.

[74] M. I. Bruce, K. Costuas, B. G. Ellis, J.-F. Halet, P. J. Low, B. Moubaraki, K. S. Murray, N. Ouddaï, G. J. Perkins, B. W. Skelton, A. H. White, Organometallics 2007, 26, 37353745.

[75] M. I. Bruce, B. G. Ellis, M. Gaudio, C. Lapinte, G. Melino, F. Paul, B. W. Skelton, M. E. Smith, L. Toupet, A. H. White, Dalton Trans. 2004, 1601-1609.

[76] M. I. Bruce, K. Costuas, T. Davin, J.-F. Halet, K. Kramarczuk, P. J. Low, B. K. Nicholson, G. J. Perkins, R. L. Roberts, B. W. Skelton, M. E. Smith, A. H. White, Dalton Trans. 2007, 5387-5399.

[77] M. I. Bruce, K. Costuas, T. Davin, B. G. Ellis, J.-F. Halet, C. Lapinte, P. J. Low, M. E. Smith, B. W. Skelton, L. Toupet, A. H. White, Organometallics 2005, 24, 3864-3881. 
[78] M. I. Bruce, B. G. Ellis, P. J. Low, B. W. Skelton, A. H. White, Organometallics 2003, 22, 3184-3198.

[79] H. Jiao, K. Costuas, J. A. Gladysz, J.-F. Halet, M. Guillemot, L. Toupet, F. Paul, C. Lapinte, J. Am. Chem. Soc. 2003, 125, 9511-9522.

[80] F. Coat, M.-A. Guillevic, L. Toupet, F. Paul, C. Lapinte, Organometallics 1997, 16, 59885998.

[81] P. J. Low, Dalton Trans. 2005, 2821-2824.

[82] N. J. Tao, Nat. Nanotechnology 2006, 1, 173-181.

[83] D. C. Milan, A. Vezzoli, I. J. Planje, P. J. Low, Dalton Trans. 2018, 47, 14125-14138.

[84] Y. Tanaka, M. Kiguchi, M. Akita, Chem. Eur. J. 2017, 23, 4741-4749.

[85] P. Belanzoni, N. Re, A. Sgamellotti, C. Floriani, J. Chem.Soc., Dalton Trans. 1998, 18251836.

[86] F. Zhuravlev, J. A. Gladysz, Chem. Eur. J. 2004, 10, 6510-6522.

[87] C. Herrmann, J. Neugebauer, J. A. Gladysz, M. Reiher, Inorg. Chem. 2005, 44, 6174-6182.

[88] M. Parthey, M. Kaupp, Chem. Soc. Rev. 2014, 43, 5067-5088.

[89] L. Pu, Z. Zhang, R. B. King, W. D. Allen, Phys. Chem. Chem. Phys. 2018, 20, 1549615506.

[90] J. Neugebauer, M. Reiher, J. Phys. Chem. A 2004, 108, 2053-2061.

[91] N. Ouddaï, K. Costuas, M. Bencharif, J.-Y. Saillard, J.-F. Halet, C. R. Chimie 2005, 8, 1336-1350.

[92] H. Sahnoune, Z. Baranová, N. Bhuvanesh, J. A. Gladysz, J.-F. Halet, Organometallics 2013, $32,6360-6367$.

[93] A. Ladjarafi, K. Costuas, H. Meghezzi, J.-F. Halet, J. Mol. Mod. 2015, 21, 71.

[94] M. B. Robin, P. Day, Adv. Inorg. Chem. Radiochem. 1967, 10, 247-422.

[95] M. I. Bruce, P. J. Low, K. Costuas, J.-F. Halet, S. P. Best, G. A. Heath, J. Am. Chem. Soc. 2000, 122, 1949-1962. 
[96] N. Le Narvor, L. Toupet, C. Lapinte, J. Am. Chem. Soc. 1995, 117, 7129-7138.

[97] M. Guillemot, L. Toupet, C. Lapinte, Organometallics 1998, 17, 1928-1930.

[98] A. D. Becke, Phys. Rev. A 1988, 38, 3098-3100.

[99] J. P. Perdew, Phys. Rev. B 1986, 33, 8822-8824.

[100] N. S. Hush, Prog. Inorg. Chem. 1967, 8, 391-444.

[101] N. S. Hush, Electrochim. Acta 1968, 13.

[102] R. A. Marcus, Chem. Phys. Lett. 1987, 133, 471-473.

[103] D. M. D’Alessandro, F. R. Keene, Chem. Soc. Rev. 2006, 35, 424-440.

[104] J.-P. Launey, C. Coudret, C. Hortholary, J. Phys. Chem. B 2007, 111, 6788-6797.

[105] B. S. Brunschwig, C. Creutz, N. Sutin, Chem. Soc. Rev. 2002, 31, 168-184.

[106] F. Coat, F. Paul, C. Lapinte, L. Toupet, K. Costuas, J.-F. Halet, J. Organomet. Chem. 2003, $683,368-378$.

[107] A. Burgun, F. Gendron, P. A. Schauer, B. W. Skelton, P. J. Low, K. Costuas, J.-F. Halet, M. I. Bruce, C. Lapinte, Organometallics 2013, 32, 5015-5025.

[108] N. Le Narvor, C. Lapinte, C. R. Acad. Sci., Paris, Ser. IIc 1998, 745.

[109] S. I. Ghazala, F. Paul, L. Toupet, T. Roisnel, P. Hapiot, C. Lapinte, J. Am. Chem. Soc. 2006, $128,2463-2476$.

[110] F. de Montigny, G. Argouarch, K. Costuas, J.-F. Halet, T. Roisnel, L. Toupet, C. Lapinte, Organometallics 2005, 24, 4558-4572.

[111] S. Le Stang, F. Paul, C. Lapinte, Organometallics 2000, 19, 1035-1043.

[112] S. Roué, S. Le Stang, L. Toupet, C. Lapinte, C. R. Chimie 2003, 6, 353-366.

[113] It has to be noticed that these DFT studies were performed during a long period of time, using different levels of theory (functionals and/or basis sets). Consequently, a rigorous comparison of the computed atomic spin densities is not relevant, atomic spin densities being strongly dependent of the functional used. Therefore, in order to obtain data which can be compared, electronic structures of the neutral compounds were re-evaluated at the same level of theory for this work. 
[114] S. Roué, H. Sahnoune, L. Toupet, J.-F. Halet, C. Lapinte, Organometallics 2016, 35, 20572070.

[115] U. Pfaff, A. Hildebrandt, M. Korb, D. Schaarschmidt, M. Rosenkranz, A. Popov, H. Lang, Organometallics 2015, 34, 2826-2840.

[116] D. J. Armitt, M. I. Bruce, M. Gaudio, N. Zaitseva, B. W. Skelton, A. H. White, B. Le Guennic, J.-F. Halet, M. A. Fox, R. L. Roberts, F. Hartl, P. J. Low, Dalton Trans. 2008, 67636775.

[117] M. A. Fox, B. Le Guennic, R. L. Roberts, D. A. Brue, D. S. Yufit, J. A. K. Howard, G. Manca, J.-F. Halet, F. Hartl, P. J. Low, J. Am. Chem. Soc. 2011, 133, 18433-18446.

[118] K. Boguslawski, C. R. Jacob, M. Reiher, J. Chem. Theory Comput. 2011, 7, 2740-2752.

[119] F. Neese, Coord. Chem. Rev. 2009, 253, 526-563.

[120] T. Weyland, K. Costuas, L. Toupet, J.-F. Halet, C. Lapinte, Organometallics 2000, 19, 4228-4239.

[121] K. Costuas, O. Cador, F. Justaud, S. Le Stang, F. Paul, A. Monari, S. Evangelisti, L. Toupet, C. Lapinte, J.-F. Halet, Inorg. Chem. 2011, 50, 12601-12622.

[122] R. Makhoul, H. Sahnoune, V. Dorcet, J.-F. Halet, J.-R. Hamon, C. Lapinte, Organometallics 2015, 34, 3314-3326.

[123] Y. Lu, R. Quardokus, C. S. Lent, F. Justaud, C. Lapinte, S. A. Kandel, J. Am. Chem. Soc. 2010, 132, 13519-13524.

[124] R. Quardokus, Y. Lu, N. A. Wasio, C. S. Lent, F. Justaud, C. Lapinte, S. A. Kandel, J. Am. Chem. Soc. 2012, 134, 1710-1714.

[125] N. Gauthier, N. Tchouar, F. Justaud, G. Argouarch, M. P. Cifuentes, L. Toupet, D. Touchard, J.-F. Halet, S. Rigaut, M. G. Humphrey, K. Costuas, F. Paul, Organometallics 2009, 28, 2253-2266.

[126] F. Gendron, A. Burgun, B. W. Skelton, A. H. White, T. Roisnel, M. I. Bruce, J.-F. Halet, C. Lapinte, K. Costuas, Organometallics 2012, 21, 6796-6811.

[127] A. Burgun, F. Gendron, C. J. Sumby, T. Roisnel, O. Cador, K. Costuas, J.-F. Halet, M. I. Bruce, C. Lapinte, Organometallics 2014, 33, 2613-2627. 
[128] P. J. Low, Electrochim. Acta 2013, 110, 681-692.

[129] M. Parthey, J. B. G. Gluyas, M. A. Fox, P. J. Low, M. Kaupp, Chem. Eur. J. 2014, 20, 6895-6908.

[130] F. Paul, F. Malvolti, G. Da Costa, S. Le Stang, F. Justaud, G. Argouarch, A. Bondon, S. Sinbandhit, K. Costuas, L. Toupet, C. Lapinte, Organometallics 2010, 29, 2491-2502.

[131] F. Paul, G. Da Costa, A. Bondon, N. Gauthier, S. Sinbandhit, L. Toupet, K. Costuas, J.-F. Halet, C. Lapinte, Organometallics 2007, 26, 874-896.

[132] S. Gückel, J. B. G. Gluyas, S. El-Tarhuni, A. N. Sobolev, M. W. Whiteley, J.-F. Halet, C. Lapinte, M. Kaupp, P. J. Low, Organometallics 2018, 37, 1432-1445.

[133] C. C. Pye, T. Ziegler, Theor. Chem. Acc. 1999, 101, 396-408.

[134] M. Cossi, N. Rega, G. Scalmani, V. Barone, J. Chem. Phys. 2001, 114, 5691.

[135] V. Barone, M. Cossi, J. Phys. Chem. A 1998, 102, 1995-2001.

[136] C. S. Lent, P. D. Tougaw, W. Porod, G. H. Bernstein, Nanotechnology 1993, 4, 49-57.

[137] C. S. Lent, P. D. Tougaw, W. Porod, Appl. Phys. Lett. 1993, 62, 714.

[138] A. O. Orlov, I. Amlani, G. Toth, C. S. Lent, G. H. Bernstein, G. L. Snider, Appl. Phys. Lett. 1999, 74, 2875.

[139] C. S. Lent, Science 2000, 288, 1597-1599.

[140] H. Qi, S. Sharma, Z. Li, G. L. Snider, A. O. Orlov, C. S. Lent, T. P. Fehlner, J. Am. Chem. Soc. 2003, 125, 15250-15259.

[141] Z. Li, T. P. Fehlner, Inorg. Chem. 2003, 42, 5715-5721.

[142] H. Qi, A. Gupta, B. C. Noll, G. L. Snider, Y. Lu, C. S. Lent, T. P. Fehlner, J. Am. Chem. Soc. 2005, 127, 15218-15227.

[143] T. Groizard, S. Kahlal, J.-F. Halet, J. Organomet. Chem. 2017, 844, 35-42.

[144] J. A. Christie, R. P. Forrest, S. A. Corcelli, N. A. Wasio, R. Quardokus, R. Brown, S. A. Kandel, Y. Lu, C. S. Lent, K. W. Henderson, Angew. Chem. Int. Ed. 2015, 54, 15448-15451.

[145] W. Z. Heisenberg, Z. Phys. 1926, 38, 411. 
[146] P. A. M. Dirac, Proc. R. Soc. London 1929, 123, 714.

[147] J. H. van Vleck, The Theory and Magnetic Susceptibilities, Oxford University Press, Oxford, 1932.

[148] N. A. G. Bandeira, B. Le Guennic, J. Phys Chem. A 2012, 116, 3465-3473.

[149] N. Onofrio, J.-M. Mouesca, Inorg. Chem. 2011, 50, 5577-5586.

[150] L. Noodleman, J. Chem. Phys. 1981, 74, 5737-5743.

[151] F. Gendron, J. Autschbach, J.-P. Malrieu, H. Bolvin, Inorg. Chem. 2019, 58, 581-593.

[152] M. Nishino, Y. Yoshioka, K. Yamaguchi, Chem. Phys. Lett. 1998, 297, 51-59.

[153] E. Ruiz, J. Comput. Chem. 2011, 32, 1998-2004.

[154] G. David, F. Wennmohs, F. Neese, N. Ferré, Inorg. Chem. 2018, 57, 12769-12776.

[155] E. Coulaud, J.-P. Malrieu, N. Guihéry, N. Ferré, J. Chem. Theory Comput. 2013, 9, 3429_ 3436.

[156] N. Ferré, N. Guihéry, J.-P. Malrieu, Phys. Chem. Chem. Phys. 2015, 17, 14375-14382.

[157] S. Kheradmandan, K. Venkatesan, O. Blacque, H. W. Schmalle, H. Berke, Chem. Eur. J. 2004, 10, 4872-4885.

[158] F. Paul, A. Bondon, G. Da Costa, F. Malvolti, S. Sinbandhit, O. Cador, K. Costuas, L. Toupet, M.-L. Boillot, Inorg. Chem. 2009, 48, 10608-10624.

[159] J.-P. Launey, Chem. Soc. Rev. 2001, 30, 386-397.

[160] J.-P. Launey, Polyhedron 2015, 86, 151-166. 


\section{Table of Contents Graphics}

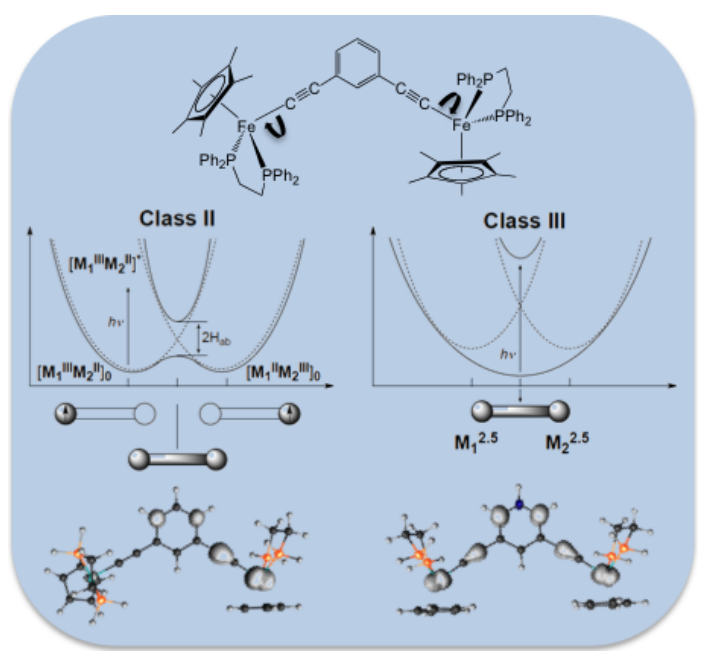

\section{Table of Contents Synopsis}

Molecular organometallic wires in which two redox-active metal termini are linked by a carbonrich bridge display interesting electronic and/or magnetic properties. This review illustrates how, in synergy with experiments, computational results can provide additional valuable information on the nature of the localized vs. delocalized electronic communication in the mono-oxidized mixed-valence species, or the magnetic coupling differences and characteristics of the di-oxidized complexes.

\section{Keywords}

Carbon-rich compounds - Density functional theory - Electronic structure - Mixed-Valence - Magnetism - Organometallic complexes - Organometallic wires

\section{Key Topic}

Organometallic wires 